Journal of the History of Biology (2014) 47:501-546 (c) The Author(s). This article is published with open access at Springerlink.com 2014 DOI $10.1007 / \mathrm{s} 10739-014-9383-2$

\title{
Mendelian-Mutationism: The Forgotten Evolutionary Synthesis
}

\author{
ARLIN STOLTZFUS \\ Institute for Bioscience and Biotechnology Research \\ 9600 Gudelsky Drive \\ Rockville, MD 20850 \\ USA \\ E-mail: arlin@umd.edu \\ Biosystems and Biomaterials Division \\ NIST \\ 100 Bureau Drive \\ Gaithersburg, MD 20899 \\ USA \\ KELE CABLE \\ Program in the History of Science and Technology \\ University of Minnesota \\ 108 Pillsbury Hall, 310 Pillsbury Drive SE \\ Minneapolis, MN 55455-0231 \\ USA \\ E-mail: cable020@umn.edu
}

\begin{abstract}
According to a classical narrative, early geneticists, failing to see how Mendelism provides the missing pieces of Darwin's theory, rejected gradual changes and advocated an implausible yet briefly popular view of evolution-by-mutation; after decades of delay (in which synthesis was prevented by personal conflicts, disciplinary rivalries, and anti-Darwinian animus), Darwinism emerged on a new Mendelian basis. Based on the works of four influential early geneticists - Bateson, de Vries, Morgan and Punnett -, and drawing on recent scholarship, we offer an alternative that turns the classical view on its head. For early geneticists, embracing discrete inheritance and the mutation theory (for the origin of hereditary variation) did not entail rejection of selection, but rejection of Darwin's non-Mendelian views of heredity and variation, his doctrine of natura non facit saltum, and his conception of "natural selection" as a creative force that shapes features out of masses of infinitesimal differences. We find no evidence of a delay in synthesizing mutation, rules of discrete inheritance, and selection in a Mendelian-Mutationist Synthesis. Instead, before 1918, early geneticists had conceptualized allelic selection, the Hardy-Weinberg equilibrium, the evolution of a quantitative trait under selection, the probability of fixation of a new mutation, and
\end{abstract}


other key innovations. Contemporary evolutionary thinking seems closer to their more ecumenical view than to the restrictive mid-twentieth-century consensus known as the Modern Synthesis.

Keywords: Mutationism, Darwinism, de Vries, Morgan, Bateson, Punnett

\section{Introduction}

The scientists who embraced the early findings of genetics - particulate inheritance, mutation, and the inefficacy of selection in a pure line - are known as "Mendelians," "early geneticists" or sometimes, "mutationists." Although historical treatments of the Mendelians' evolutionary views are often contradictory, the elements of what we will call a "classical view" may be discerned in early writings of the Modern Synthesis, particularly Fisher $(1930,1932)$ and J. Huxley (1942), and in later works of history by Eiseley (1958), Provine (1971), Allen (1978, pp. 106-125), Mayr (1982), and Bowler (1978, 1983, 1988). ${ }^{1}$

According to Bowler (2003), the evolutionary views of Mendelians and other non-Darwinians typically are seen as a "blind alley," separate from the "main line leading from Darwin to modern Darwinism" (p. 224). The classical view holds that, though genetics is the "perfect complement" to Darwin's theory (Provine, 1971, p. 130), literally supplying its "missing parts" (Froggatt and Nevin, 1971, p. 22), early geneticists failed to see this, resulting in a "delay in applying Mendelian principles to an understanding of evolution" (Allen, 1969, p. 61; Provine, 1971, p. 177). The early geneticists opposed natural selection (e.g., Provine, 1971, Ch. 4; Allen, 1980; Mayr, 1982, p. 546; Bowler, 1988, pp. $117-125 ; 2003$, p. 308$),{ }^{2}$ and imagined that evolution must take place by major discontinuities, dismissing a role for smooth change based on continuous variation (Provine, 1971, p. 89; Allen, 1980; Mayr, 1980; Bowler, 1988, p. 122; Mayr, 1988, p. 107, 1991).

In the classical view, it takes several decades to correct these misimpressions: (1) de Vries's Oenothera mutants are revealed as

${ }^{1}$ Bowler subverts the classical narrative in ways noted below. Provine's account is sufficiently rich as to support alternative readings, as will become apparent below.

${ }^{2}$ The theme of opposition is consistent, but it is often unclear what this opposition signifies. For instance, Provine's text provides many indications that early Mendelians invoked selection, yet repeatedly references an opposition between (1) "selection," "Darwinian selection theory," or "the efficacy of selection" and (2) Mendelians, "mutation," or "discontinuous evolution" (Ch. 4). 
chromosomal abnormalities based on hybridization, not true gene mutations (Bowler, 2003, pp. 269, 327; Provine, 1971, pp. 121-122; Eiseley, 1958, p. 251; Mayr, 1982, pp. 546, 743); (2) the concept of "mutation" is revised to allow changes with small effects, based on Morgan's mutant white-eyed fly (e.g., Provine, 1971, pp. 109, 121; Mayr, 1982, pp. 752, 774; Allen, 1980, p. 371); (3) a multiple-factor view emerges in which evolution takes place by selection of recombinations among alleles at multiple loci, without new mutations (Provine, 1971, pp. 108-129; Mayr, 1980, 1994).

Evidently these internal factors are not considered sufficient to account for the "inexplicable embarrassment" (Hull, 1985) of a decadeslong eclipse, inviting the search for external factors. ${ }^{3}$

However, rather than searching for external factors, one might consider instead that the internalist framework of the classical narrative is mistaken. In fact, its key features are contradicted frequently (even in classical sources). The Mendelians' alleged opposition to selection is problematic, as is their alleged rejection of small changes. Gayon argues that "the Mendelians were responsible for the operational definition of natural selection that is most widely used today - the diffusion of a gene in a population" (Gayon, 1998, pp. 181-182). Both Nordmann (1992) and Peterson (2008) reject the classical view of Bateson as the antiDarwinian whose misunderstandings delayed the Modern Synthesis. Whereas Provine depicts Bateson as the radical advocate of evolution by "discontinuous leaps" (p. 42), he quotes statements in which Bateson invokes "the subsequent perfection" of a form "by a slow process of selection" (p. 46), and a Mendelian basis for superficially continuous change "when the unit of segregation is small" (p. 69). According to Gould (2002, p. 443), de Vries was a strong advocate of selection. Bowler (1978) and Theunissen (1994, p. 244) indicate that de Vries assumed neither that all mutations create new species, nor that they always represent large or saltatory effects. Apparently, if the Mendelians opposed selection and gradual change in some ways, they embraced them in others.

3 See Smocovitis (1996) for an entree to this literature. The most prominent theme is that different schools or disciplines owned different parts of the truth, and synthetic thinking was prevented by conflicts, including personal conflicts (Froggatt and Nevin, 1971; Provine, 1971) and disciplinary rivalries, e.g., between "naturalists" and experimentalists (e.g., Kingsland, 1991). Many authors invoke an atmosphere of prejudice or irrational opposition to Darwin or his thinking (Bowler, 1988, Ch. 5; Allen, 1969, 1980, p. 368; Kingsland, 1991). Others invoke a cognitive deficiency of early geneticists, such that they were muddled, confused, or unable to think synthetically (e.g., Froggatt and Nevin, 1971; Allen, 1980, pp. 356, 373, 374). 
Other works calls into question an alleged decades-long eclipse in synthetic thinking. In Kim's analysis (1994; see also Buttolph, 2008), the Mendelian students of Bateson and Pearson (whose students mostly defected to Mendelism) quickly develop the multiple-factor theory addressing the potential for selected change on a range of quantitative variation. Similarly, Gayon argues that "the fundamental doctrines of quantitative genetics were developed early in the century, long before the publication of Fisher's canonical article of 1918 which is often credited with having laid the foundations of the discipline" (Gayon, 1998, p. 316). Even Provine's (1971) account, when read closely, fails to reveal a decades-long failure of synthesis. ${ }^{4}$

The "missing piece" theory is criticized by Bowler (1988, pp. 106, $113,130)$ for its implication, clearly mistaken, that Darwin had no substantive view of heredity and variation. Bowler (1988) and others (e.g., Winther, 2000) draw attention to the profound differences between a nineteenth-century view of heredity, variation and evolution as manifestations of growth and development - a "developmental viewpoint that Darwin had left largely intact" (Bowler, 1988, p. 114) -, and the Mendelian view of pure factors unaffected by growth, metabolism, and external conditions. Darwin recognized a direct influence of the environment and of use-and-disuse on heredity, believing that all variation is triggered by environment (Winther, 2000). Stubbe (1972, p. 219) writes that Darwin built his theory mistakenly on "secondary forms of variability, namely, variations in the phenotype caused by external influences."

The premise that Mendelism is the perfect complement to Darwin's theory is further subverted in Gayon's Darwinism's Struggle for Survival (1998), which argues that Darwin's original conception of "natural

\footnotetext{
${ }^{4}$ Chapter 4 of Provine (1971) depicts (1) an early period of building synthetic concepts and obtaining key results (featuring the work of Johannsen, East, Nilsson-Ehle and Castle) that began immediately in 1900 and was largely complete by 1911 or 1912, when these key findings were "well known" (p. 121) to geneticists, followed by (2) a brief period during which, Provine alleges, resistance to generalizations based on these results gave way to consensus by 1918 or 1919 (see p. 108). After these conceptual and experimental foundations are in place, a mathematical theory is built by Fisher, Haldane and Wright in the 1920s. Provine's account reveals that each of the three pre-1920 theoretical milestones - the Hardy-Weinberg equilibrium (1908), the allelic selection model (1915), and Fisher's quantitative trait model (1918) -, was preceded by a series of even earlier (often flawed or incomplete) theoretical results. In other words, the facts of Provine's account show the period of 1900-1918 to be, not a period of stultifying delay, but a period of dizzying experimental, conceptual and theoretical innovation.
} 
selection" depends on blending inheritance. This built-in conflict with the discrete basis of heredity represents a "principled crisis" or "founding crisis" (pp. 1-15) that ends with "the most important event in the history of Darwinism" (p. 289): geneticists re-conceive selection as a force that shifts frequencies of true-breeding types. The new concept then could be used (by Fisher and others) to show how selection on a recombining mass of small-effect genetic variations could produce a smooth adaptive shift in phenotypes, mimicking Darwin's theory using a different mechanism.

A more thorough analysis of the evolutionary views of early geneticists might clarify, not only issues of interest to historians, but ongoing issues of theory-evaluation among scientists. When scientists relate how the discovery of genetics affected evolutionary thinking, they nearly always invoke a caricature of the classical view in which bumbling geneticists fail to find the missing piece, and foolishly imagine that evolution happens by dramatic mutations alone, without selection (e.g., Dawkins, 1987, p. 305; Cronin, 1991, p. 47; Ayala and Fitch, 1997; Eldredge, 2001, p. 67; Segerstråle, 2002; Charlesworth and Charlesworth, 2009). Accordingly, when scientists list major evolutionary figures, a large gap appears between nineteenth- and twentieth-century progenitors. ${ }^{5}$ Surely the ongoing scientific debate over the meaning and status of the twentieth-century Darwinian synthesis, which often makes reference to history (e.g., Pigliucci, 2009; Chouard, 2010), would benefit from an accurate history of this early period, and in particular, would benefit from a clearer picture of how a Mendelian view that combines genetics and selection could be so non-Darwinian as to have been thoroughly excluded.

Here we aim to present the Mendelian alternative to Darwinism from the perspective of those who developed it, not those who rejected it. Our analysis focuses narrowly on scientific (not external) arguments based

5 For instance, the contemporary Oxford Encyclopedia of Evolution (Pagel, 2002) has a biographical entry for Mendel - who made no direct contributions to evolutionary theory -, but lacks entries for Bateson, de Vries, Johannsen, and Punnett; the entry for Morgan says nothing of his evolutionary views. The historical timeline of influential thinkers in a popular educational resource (http://www.ucmp.berkeley.edu/history/ evotmline.html) goes from Darwin, Weismann, and others in the late nineteenth century, then jumps to Wright, Fisher, et al., indicating a lack of key contributions for about three decades. 
on key works of de Vries, Bateson, Morgan and Punnett, whom we take to be foremost among the early geneticists (see Buttolph, 2008) known for their evolutionary heterodoxy during the alleged "eclipse." The first three are unarguably the early geneticists implicated most often in the classical view. Hugo de Vries, the Dutch botanist, published his $\mathrm{Mu}$ tationsTheorie (1901) in German, but also published in English (de Vries, 1905), and lectured in the US repeatedly before 1910. The British geneticist William Bateson wrote Materials for the Study of Variation (1894) before becoming the foremost interpreter and defender of Mendelism in the English-speaking world (Bateson and Saunders, 1902; Bateson, 1902, 1909a, b). Thomas Hunt Morgan, the American embryologist and geneticist who later won a Nobel Prize for his work on genetics, wrote several books on evolution (Morgan, 1903, 1916, 1925, 1932). To these three, we add Reginald Crundall Punnett, ${ }^{6}$ whose Mendelism $(1905,1911,1915)$, the first textbook of genetics, presented a synthetic view of evolution, and was translated into multiple languages, going through new editions every few years until the late 1920s (Crew, 1968).

First, on the basis of these works, we describe the mutationist critique of Darwin's theory, which rejects the heritability of environmentally-induced fluctuations; rejects Darwin's doctrine of natura non facit saltum; and rejects the claim that natural selection is creative. The early geneticists' skepticism in regard to smooth change based on continuous variation, almost universally misconstrued, was

${ }^{6}$ Punnett's stature is indicated by (1) his debate with Poulton over the evolution of mimicry, culminating in an early book (Punnett, 1915) targeted for criticism by Fisher, and still cited by scientists (e.g., Balogh and Leimar, 2005) as a historic touchstone, and (2) direct historic references such as Wallace's (1909) personal criticism of "Bateson, Punnett, de Vries and Company" as "the self-deluded specialists" of the new view, and Reid's (1913) attack on the "Mendelo-Mutationists" targeting Bateson, Punnett and Morgan. Other early geneticists of interest include Wilhelm Johannsen, Charles Davenport, Lucien Cuénot, Robert Heath Lock, and Richard Goldschmidt. All but Goldschmidt are recognized in Buttolph's (2008) study as early geneticists, active in the first decade of the twentieth century. Johannsen's experimental results were profoundly influential, but the direct influence of Johannsen's evolutionary thinking was, we suspect, less than that of Punnett. Lock (1906), Davenport (1909), Cuénot (1909), and Goldschmidt (1911) similarly appear to have been secondary influences on evolutionary discourse in the early period of interest here. Goldschmidt later became well known as an advocate of macromutations (Dietrich, 2003). 
predominantly a narrow, experimentally justified rejection of Darwin's non-Mendelian view based on environment-stimulated fluctuations. Second, we describe a generalized Mendelian-Mutationist view and list eight areas in which the synthetic thinking of early geneticists remains relevant to contemporary science. We note that non-Darwinian ideas have re-entered contemporary evolutionary biology to such a degree that the Mendelian-Mutationist synthesis should be reconsidered as the foundation of evolutionary thought. We suggest, contrary to the classical view, that the revolutionary synthetic period in evolutionary thinking is from 1900 to 1930, and the embarrassing eclipse is the subsequent period of orthodoxy that, for several decades, convinced historians and scientists to imagine that genetics is the missing piece of a Darwinian theory that accounts generally for evolution.

\section{Mutation, Selection, and the Mutationist Critique}

Before presenting the Mendelians' positive views of evolution, we present their critique of Darwin's theory of natural selection. To contextualize this critique, we must explain what "mutation" and "natural selection" meant to early geneticists.

The Theory of Mutation

Controlled breeding experiments using Mendelian differences revealed that some kind of factor must pass (via gametes) from grandparent to parent to child in a pure form, not blended or corrupted. Just as a complex chemical mixture - to use a favorite metaphor of de Vries (1909a, p. 3) - ultimately resolves to combinations of discrete and constant elements, so do organisms. Mendelism is not a theory of growth-like change, but a theory of chemical constancy with conservative reconfigurations. Such a view begs for a theory of mutation, as Pearson (1906) argues (see also Shull 1907):

... there must be a manifest want in Mendelian theories of inheritance. Reproduction from this standpoint can only shake the kaleidoscope of existing alternatives; it can bring nothing new into the field. To complete a Mendelian theory we must apparently associate it for the purposes of evolution with some hypothesis of 
"mutations." The chief upholder of such an hypothesis has been de Vries... (p. 39)

The terms "mutation,"7 "mutation theory", and "mutationist" rose to prominence soon after de Vries's (1901) MutationsTheorie, which raises the question of whether a "mutationist" or advocate of "the mutation theory" is (1) an advocate of a general theory proposing that genetic factors change by discrete events, or (2) an advocate of de Vries's special views. De Vries recognized several categories of mutations, as distinct from fluctuations, the most important being "progressive" mutations that arise only during rare "mutation periods" and generate reproductively isolated species with new characters (Theunissen, 1994; Stamhuis et al., 1999). He allowed for temporary change by selection of fluctuations, which he held to have limited heritability (Theunissen, 1994, p. 229; Meijer, 1985, pp. 199, 208).

In the passage quoted above, Pearson's use of "some hypothesis" (of mutation) and "such an hypothesis" implies that, for him, de Vries's special view is merely one instance of a general concept of mutational shifts. Morgan (1903) likewise invokes mutation in a more general way:

It should be stated here, at the outset, that the term mutation will be used in the following chapters in a very general way, and it is not intended that the word shall convey only the idea which De Vries attaches to it; it is used rather as synonymous with discontinuous and also definite variation of all kinds. (p. 340)

${ }^{7}$ In writings of this period, it may be hard to tell whether "mutation" refers to a variant form, an event, a difference, a process, or something else. In our sources, concrete references (e.g., "it is a mutation," "the dwarf mutation") typically are best understood as references to a variant phenotypic form, with the implication that this form arose by a process of mutation, and is the realization of a discrete genetic class. For instance, when Punnett says that "The dwarf mutation is subject to fluctuating variations which are probably due to the environment peculiar to each individual" (1905, p. 49), it is clear that the "mutation" refers to a genotypically-defined class comprising individual phenotypic forms, which is subject to environmental sources of variance, rather than to the underlying genotype, which is not. As researchers began to distinguish transmission genetics from developmental genetics, "mutation" began to take on the modern sense of a transmissible genetic change, as distinct from its phenotypic effects. 
In context, "definite" means having a distinctive and constant aspect, such as may recur recognizably in progeny. Likewise, Bateson (1909b) writes ${ }^{8}$ :

We may be doubtful of the validity of the superstructure which de Vries has created, and yet in full agreement with him in recognizing the fundamental truth, that there is a natural distinction between fluctuational variations and actual genetic variations; that the latter are those alone by which permanent evolutionary change of type can be effected; and that commonly, though, as it seems to me, not always, the steps by which such changes occur are so discontinuous as to merit the name Mutations. (p. 287)

Morgan (above), as well as Punnett (quoted below) tended to imply that "mutations" are, per definitionem, the kinds of variations that are heritable, whether they are large or small, while Bateson distinguishes "actual genetic" variations from fluctuations. Other geneticists of this era also invoked mutation or "mutation theory" as a generic theory of hereditary variation, not tied to the size of variation, but to heritability:

There is no saying, with respect to any particular variation, whether it may belong to the one or to the other class, before the actual test (pedigree-culture) [to determine if the variation is inherited] has been made, although it seems that mutations often or generally differ from fluctuating variations in the degree of deviation from the original form. This is the essence of the mutation theory. (Ortmann 1907)

Mutations can only be recognized as such with certainty when they arise in pure-bred strains. They are not to be distinguished from fluctuations by being large and striking variations but by the fact that they represent a fundamental change in the internal composition or structure of the vital substance, which renders the characteristic qualities of the new form transmissible through sexually produced seeds. Variations that are thus transmitted are often very insignificant, quantitatively, compared with others that are not so transmitted. (Shull 1907, p. 61)

By contrast, the classical view claims that "mutations" initially referred to dramatic species-creating mutations, and shifted in meaning only when Morgan's white-eyed mutant fly revealed in 1910 that mutations

${ }^{8}$ Bateson's doubts about de Vries's "superstructure" partly reflect the suspicion, later proved correct, that the Oenothera mutants represent a special case based on "some unsuspected original cross," i.e., hybridism (Bateson and Saunders 1902, p. 156, note 2). 
could be small in effect, and when Davis's studies (1912-1915) undermined the significance of de Vries's Oenothera mutants (e.g., Allen, 1969, 1980; Provine, 1971, p. 109; Mayr, 1980, 1982, pp. 752, 774; 1991, p. 133). None of these authors explain by what standard a white-eyed fly is considered a "small" variation relative to well known examples - e.g., Mendel's wrinkled peas, or Johannsen's differently sized beans - that were assumed to have arisen by some unobserved mutation in the past. In fact, as shown above, geneticists already accepted that mutations could be smaller than ordinary fluctuations, whereas white-eyed flies are outside the normal range of variation (which is precisely why they caught Morgan's attention). For instance, Richmond (2006, p. 471) quotes from a 1909 work by Shipley, who explains his view allowing small mutations by quoting Punnett (1905):

Doubtless some of the so-called fluctuations are in reality small mutations, whilst others are due to environmental influence... The simultaneous existence of small mutations and large fluctuations leads to the disguising of the former by the latter. (p. 51)

The fact that multiple authors invoked such mutations, which were too small to be detected experimentally, suggests that their existence was inferred in some way, as indicated when Punnett (1905) writes, "a cursory examination of the horticultural literature must convince anyone, that it is by selection of mutations, often very small, that the gardener improves his varieties" (pp. 52-53). Clearly the notion of a 1910 shift in the connotations of "mutation" does not apply to early geneticists. ${ }^{9}$

\section{Natural Selection in Historical Context}

The idea of "natural selection" invoked by scientists today has been reconfigured to fit a world of discrete inheritance (Gayon 1998). In such a world, it is natural to imagine that change might begin with some rare trait that confers a small advantage, e.g., $2 \%$, so that individuals with the trait tend to leave more offspring that, in turn, inherit the $2 \%$ advantage and leave more offspring. Over time, the trait increases in frequency until it prevails. To a contemporary reader, this is "natural selection."

Such a process of "natural selection" cannot occur in Darwin's world, in which hereditary substances are inconstant even in an indi-

9 This would include Johannsen (see Roll-Hansen 1989, p. 319) and perhaps others such as Castle (1905). 
vidual's lifetime, and lose their identity entirely each generation, due to blending during reproduction (Winther, 2000). As Gayon (1998) explains, by reference to Fleeming Jenkin's famous critique:

as Jenkin points out, Darwin's theory is 'surely not' that the advantage given by a sport is retained in its descendants. The only hypothesis of heredity under which natural selection would clearly be effective is not the one advanced by Darwin. To admit that selection only consists in spreading prepotent anomalies would be to accept that nature proceeds by leaps. (p. 91)

Instead, in Darwin's view, the struggle for life shapes organisms by leveraging many small separate differences that blend together in offspring. If 50 individuals have thicker fur, this is not due to a pure factor they inherited from a common ancestor, but because, out of all the indefinite variations stimulated by conditions of life, 50 happened to go in the direction of thicker fur. If these differences contribute to success in the struggle for life, they will be summed and blended in the next generation.

Both the Mendelian and the Darwinian view allow the complete transition from an ancestor population with one state, to a descendant population with another state. The difference emerges when one imagines the half-way point: in a Mendelian or Jenkinian world, $50 \%$ of the population has the new state, and there is no intermediate in which $100 \%$ of the population has changed halfway. ${ }^{10}$ By contrast, in the Darwinian world, blending makes the converse true: at the halfway point, $100 \%$ of the population has changed halfway, but there is no point at which $50 \%$ has changed all the way. If we allow a bit of random noise, these two views might look the same when the change involves a few extra hairs on a fly's abdomen, but they cannot look the same if the change involves an extra pair of wings. In the Darwinian view, these two states must be separated by thousands of phenotypic intermediates.

Thus, when Darwin says that "natural selection can act only by the preservation and accumulation of small inherited modifications"

\footnotetext{
${ }^{10}$ One might imagine, as an extreme case, a Mendelian world in which selection takes place simultaneously on pre-existing variation at many recombining loci, with the variation at each locus having a tiny effect. Throughout an episode of change, the population shows a smooth distribution (e.g., a bell curve) that shifts gradually. At the halfway point, the mean value is halfway between the ancestral and the derived state. This scenario makes the Mendelian world look superficially like the Darwinian one, though on an entirely different mechanistic basis. As discussed below, this is precisely the scenario invoked by Darwin's mid-twentieth-century followers to argue that Mendelian genetics supplies the missing pieces of Darwin's theory.
} 
(Darwin, 1872, Ch. 4) or that his theory would "utterly break down" if it could be shown that any feature had not arisen by numerous successive slight modifications, he is not making a logical error, and he is not restricting a modern (generic) principle of selection with an extrinsic doctrine of gradualism. Instead, smooth change is mechanistically intrinsic to Darwin's conception of "natural selection": Darwin says explicitly that natura non facit saltum "must on this theory be strictly true" (Darwin, 1872, Ch. 6).

\section{The Mutationist Critique: Saltation, Fluctuation and Creativity}

With the above background, it is now possible to present the mutationist critique of Darwin's theory. The first key component of this critique was the argument for saltation or discontinuity: some evolutionary changes have the quality of jumps. The early geneticists developed and extended an argument for saltation based on the plausibility of discontinuous (definite) variations as the basis of evolutionary change, beginning with Bateson's Materials for the Study of Variation (1894), a compendium of 886 cases of discontinuous variants, and continuing with de Vries's Die MutationsTheorie (1901).

Bateson, de Vries, Morgan and others (e.g., Davenport 1909) did not focus solely, nor even largely, on the notion that some variations are quantitatively large. Instead, they focused on variations being discontinuous or definite, words used frequently and apparently interchangeably by Bateson (1909b, p. 286) and Morgan (1904, p. 60), though there is a subtle difference in connotation. There is no conceptual difficulty in imagining the gradual appearance, by a thousand infinitesimal increments, of an extra petal on a flower, or an extra finger on a hand, or an extra vertebra in a neck or tail: in each case, we can imagine the feature appearing one cell, or one molecule, at a time. Yet, Bateson and others were impressed with observations suggesting that fully formed parts may appear suddenly, without intermediates or preparatory stages, and persist in progeny, obviously without having been brought into existence by a slow process of selection. The resulting variants have a property of definiteness, which may be invoked with words such as "definite" or "definitely constituted" (e.g., Morgan, 1903, pp. 95, 261, 340; 1904, p. 60; Bateson, 1894, pp. 64, 65), "complete" (Bateson, 1894, p. 65), "orderly" (Bateson, 1909a), or "well developed" (Davenport, 1909).

Darwin himself allowed that, under domestication, striking new forms may appear suddenly and be "transmitted in a perfect state" 
(Darwin, 1868, Ch. 15). He depicted such forms as monsters, and claimed that he "failed to find, after diligent search, cases of monstrosities resembling normal structures in nearly allied forms, and these alone bear on the question" (Darwin, 1872, Ch. 2). By contrast, Bateson (1909b) argued that "inasmuch as the discontinuity of variation is manifested again and again in respect of exactly those differences which we are accustomed to recognize as distinguishing specific forms from each other, the further conclusion followed that the diversity of species may be regarded as having come about very largely by the occurrence of these discontinuous variations" (p. 286).

Thus, the saltationist argument is that (1) there is a process giving rise suddenly to definite forms that differ discretely from their parents; (2) the effects of such changes are sometimes definitely heritable; and (3) such differences play a significant role in evolution, as suggested by their similarity to natural species differences. Darwin had accepted the first two points, but rejected the third.

The second component of the mutationist critique concerns fluctuations, which are distinguished from mutations by hereditary constancy, not size, as de Vries (1909b) makes clear:

Fluctuations constitute one type; they are never absent and follow the law of chance [Quetelet's law, resulting in a bell-shaped error distribution], but they do not afford the material from which to build new species. Mutations, on the other hand, only happen to occur from time to time. They do not necessarily produce greater changes than fluctuations, but such as may become, or rather are from their very nature, constant. It is this constancy which is the mark of specific characters, and on this basis every new specific character may be assumed to have arisen by mutation. (p. 73)

When de Vries asserts that fluctuations do not afford material to build new species, he does not mean they afford no material for change, only that this material is unsuitable for permanent or species-transcending change. De Vries had a theory-based interpretation of fluctuations as changes in the number (rather than the character) of pangenes, influenced by nutrition and conditions: these fluctuations are partially heritable (rather than non-heritable), and they allow a mode of selective improvement that may enhance a character (but not create one), subject to gradual reversal when selection is relaxed (Theunissen, 1994, p. 229).

Other geneticists saw the issue differently. Fluctuation was understood as a mode of non-heritable variation by Punnett (as quoted be- 
low), as well as Shull and Ortmann (as quoted above, in regard to mutation). The fact that Punnett had misinterpreted de Vries was pointed out to him by Poulton some years later (see Punnett, 1913). Bateson (1909a) misrepresents de Vries when he writes that "we must, as de Vries has shown, distinguish real, genetic, variation from fluctuational variations, due to environmental and other accidents, which cannot be transmitted" (p. 95).

The distinction between ephemeral outward variations and heritable internal changes drew much of its strength, perhaps, from Johannsen's influential series of quantitative experiments using the "Princess" variety of the common bean (Johannsen, 1909), which had achieved important results by 1903 (summarized nicely by Gayon 1998, pp. 260 266). In one set of experiments, Johannsen isolated 19 stable self-fertilizing lines, each of which produced seeds with a different average weight. Planting any single variety would produce a smooth bell-shaped distribution of seed weights, illustrating the fluctuating variability of seeds. He selected larger seeds from a pure line to plant a new generation, but the distribution of seed weights did not change, proving that this newly arising variation was not heritable and would not serve as the basis for improvement by selection.

The finding that fluctuations were not suitable for selection was understood as a refutation of Darwin's theory of natural selection:

The distinction between these two kinds of variation, so entirely different in their causation, renders it possible to obtain a clearer view of the process of evolution than that recently prevalent... Evolution only comes about through the survival of certain variations and the elimination of others. But to be of any moment in evolutionary change a variation must be inherited... This, as we have seen, is the case for those variations which we have termed mutations. For the inheritance of fluctuations, on the other hand, of the variations which result from the direct action of the environment upon the individual, there is no indisputable evidence. Consequently we have no reason for regarding them as playing any part in the production of that succession of temporarily stable forms which we term evolution. In the light of our present knowledge we must regard the mutation as the basis of evolution as the material upon which natural selection works. For it is the only form of variation of whose heredity we have any certain knowledge. 
It is evident that this view of the process of evolution is in some respects at variance with that generally held during the past half century. (Punnett, 1911, pp. 139-140)

Note that Punnett defines fluctuation by reference to environmental causes. Or, in the words of Bateson (1909b):

The conception of Evolution as proceeding through the gradual transformation of masses of individuals by the accumulation of impalpable changes is one that the study of genetics shows immediately to be false. Once for all, that burden so gratuitously undertaken in ignorance of genetic physiology by the evolutionists of the last century may be cast into oblivion. For the facts of heredity and variation unite to prove that genetic variation is a phenomenon of individuals. Each new character is formed in some germ-cell of some particular individual, at some point of time. (p. 289)

This is not a rejection of selection or small variations, but a rejection of a Darwinian process of modification reliant on the blending of masses of environmentally induced fluctuations - a process in which it is mechanistically impossible for evolutionary change to begin as Bateson suggests, with a single variant individual.

The final component of the mutationist critique is in regard to creativity. Darwin's theory was received and defended as an alternative to divine creation, with Natural Selection in the role of the creator that shapes each being to its conditions. This creative role of selection is conditional, not only upon the kinds of variations incorporated in evolution, but on whether they are incorporated individually or in masses: the creativity of selection can be defended only if features become definite and distinctive by the selectively-guided accumulation of many individually minor variations (see the excellent discussion by Gould, 2002, pp. 137 to 146). In Darwin's theory of pervasive variation, a distinctive form can not persist beyond the current generation unless selection holds it in place. But if definite and distinctive features appear spontaneously through mutation, reappear in the next generation due to inheritance alone, and particularly if they face the struggle for life separately rather than in masses, then the potential for a unified creative force of Natural Selection is lost, the "dual nature of the problem" (Morgan, 1903, p. 463) emerges, and the origin of novelty must be sought (partly or wholly) in the internal causes of variation. As Morgan (1904) argues (see also Morgan, 1903, p. 460): 
On the other hand, the theory of the survival of definite variations refers the creation of new forms to another process, namely, to a sudden change in the character of the germ. The creating has already taken place before the question of the survival of the new form comes up. After the new form has appeared the question of its persistence will depend on whether it can get a foothold (p. 64).

Similarly, de Vries (1905) argues:

Darwin discovered the great principle which rules the evolution of organisms. It is the principle of natural selection... Of course, with the single steps of evolution it has nothing to do. Only after the step has been taken, the sieve acts, eliminating the unfit. The problem, as to how the individual steps are brought about, is quite another side of the question (pp. 6-7)

Likewise, Bateson (1909a) says:

We must relegate Selection to its proper place. Selection permits the viable to continue and decides that the nonviable shall perish... Selection determines along which branch Evolution shall proceed, but it does not decide what novelties that branch shall bring forth (p. 95)

And finally, Punnett (1911) says:

we now recognize that the function of natural selection is selection and not creation. It has nothing to do with the formation of new variation. It merely decides whether it is to survive or to be eliminated. (p. 143)

This argument - based on re-conceptualizing selection, and then using the new concept against Darwinism - was not new. In fact, because this objection was voiced in Darwin's era, no speculation is required to know his position. As Poulton (1909) relates, the argument was made in 1864 by the Duke of Argyll, who complained that Darwin's theory was "not a theory of the Origin of Species at all, but only a theory on the causes which lead to the relative success and failure of such new forms as may be born into the world" (p. 45). Darwin responded

That may be a very good theory, but it is not mine, unless he calls a bird born with a beak 1/100th of an inch longer than usual 'a new birth'; but this is not the sense in which the term would usually be understood. The more I work the more I feel convinced it is by the accumulation of such extremely slight variations that new species arise. (p. 45) 
Thus, Darwin and the early Mendelians agree that a theory of evolution based on infinitesimal differences that blend in masses is fundamentally different from a theory that relies on distinctive single "births," which Darwin disavows as "not mine."

In summary, the mutationists had a substantive critique of Darwin's theory based on fluctuation, saltation and creativity. The critique of fluctuation regards the mechanism of evolution, not its superficial appearance: regardless of the outward character of variations (e.g., saltational or not), genetics vitiates Darwin's "natural selection" because, contrary to what Darwin claimed, variation has a discrete basis in germline changes that emerge rarely and are not induced by conditions. The critique of creativity, however, draws on both of the other arguments.

\section{Mendelian-Mutationism as Twentieth-Century Synthesis}

A Mendelian-Mutationist synthesis may be associated with the views of Morgan, Bateson, Punnett and (to a degree that we do not explore here) other early geneticists noted by Provine (1971), Kim (1994) and Buttolph (2008). Though de Vries advocated a theory of discrete inheritance, and is one of the "rediscoverers" of Mendel's hereditary principles, he was not a Mendelian (Meijer, 1985; Theunissen, 1994), and his particular views were not shared by the other three. Though we mention de Vries's views on speciation below, we assign him only a peripheral role in the Mendelian-mutationist synthesis (see Discussion).

By invoking such a synthesis, we mean to imply some things and not others. To the extent that a genetic transformation in evolutionary thinking divides the nineteenth century from the twentieth, this transformation is evident in the works of Bateson, Morgan and particularly Punnett, long before it is evident in works of Fisher, Haldane, or Dobzhansky. We do not mean to suggest that this theory achieved popularity, nor that it was promoted as a complete or finished theory-Morgan (1923) and Bateson (1922) both argued that a more complete theory of evolution would have to await a more complete understanding of genetics.

Overview of the Synthesis

The generic core of Mendelian-mutationist thinking is evident in Morgan's statement that "evolution has taken place by the incorporation into the race of those mutations that are beneficial to the life and reproduction of the organism" (Morgan, 1916, p. 194), or Bateson's claim that 
Definite variational changes are being continually offered, each giving an opportunity to natural or to artificial selection, and we need not hesitate to declare that of such materials the diversity of nature has been compiled. If anywhere in such a province as evolutionary science certainty may be reached, it is here. (Bateson 1909b, p. 288).

This statement invokes selection and implies the sufficiency of mutation as the source of variations for evolution. ${ }^{11}$

As a more thorough example, we draw attention to the 10-page section on evolution that appears in Punnett's book, Mendelism (1905). ${ }^{12}$ Punnett begins with explaining how Mendelian genetics "has led us to materially alter our ideas of the evolutionary process". $\mathrm{He}$ poses a generalized theory consistent with Darwin's view and his own:

The evolution of fresh species depends upon the action of natural selection on the variations that occur in living forms. Individuals of a species, which from their variations are more adapted to the environment, survive in the struggle for existence; individuals less adapted are placed at a disadvantage, and tend to perish in the competition with their more favoured kin. (p. 45)

Punnett goes on to distinguish heritable mutations from non-heritable fluctuations. Traits such as height vary or fluctuate due to environmental factors ("a little more manure in its particular patch of soil, fewer surrounding weeds, greater freedom from the attacks of pests"), but there is no evidence that such environmental fluctuations are heritable; by contrast, there is evidence that hereditary factors persist in a stable form, and change by rare mutations.

One's view of evolution, he argues, is "materially altered" on the grounds that "the small fluctuating variations are not the material on which selection works." Instead, "evolution takes place through the

${ }^{11}$ Note that we have quoted several statements from Bateson that use a term such as "actual genetic variation" or "definite variational change" where others would use the term "mutation." Bateson, in spite of being a notorious "mutationist", almost never uses the term "mutation" to describe his own thinking, e.g., he does so only once in his 1909 textbook (Bateson 1909b, p. 35). We are uncertain as to the reasons for this tendency (possibly to avoid associations with de Vries's special theory, or to avoid speculating about the unobserved origin of an observed variant).

12 The short section on evolution appears on pp. 44 to 53 of the 1905 version. An identical or nearly identical text appears in the 1907 version (pp. 64 to 74). The 1911 edition has been rewritten and expanded to include, among other things, a critique of Darwin's theory based on creativity (above), and an explanation of selection on a quantitative character (below). 
action of selection on these mutations. Where there are no mutations there can be no evolution." The conjecture that discontinuous or saltatory variations "played an important part in the production of species" is referenced and attributed to Bateson. Yet Punnett repeatedly notes that mutations may be small, and (as quoted earlier) suggests that genuine mutations may be hiding among the fluctuations.

We see little in Punnett's chapter - now 109 years old - to offend the sensibilities of a contemporary scientist, except that the works of Bateson and de Vries are referenced as correctives to Darwin's views, and that natural selection is said to "sift" variation. In the twentieth-century orthodoxy, references to selection in terms of sieves and sifting are condemned as "downright misleading," "exaggeration", or "over-simplification" (Dobzhansky, 1974), in preference to metaphors that anthropomorphize selection as an artistic creator-e.g., a painter, writer, or sculptor that shapes, molds, builds and creates out of raw materials (Gould, 1977, Ch. 4) -, which are not considered to be downright misleading.

\section{Mendelian-Mutationist Innovations, in Contemporary Context}

Bateson, Morgan, Punnett and de Vries applied new genetic ideas to evolution in many ways, some of which are not important in contemporary thinking, e.g., de Vries' theory of selection of fluctuations, or Bateson's (1914) provocative thesis of evolution entirely by loss of factors. Below we present eight areas in which the synthetic thinking of the early Mendelians is relevant to contemporary evolutionary biology. Our aim is to establish that the same scientists targeted in the classical view for being on the wrong side of Darwinism (and for failing to achieve a synthesis) developed and explored foundational concepts of evolutionary genetics that remain relevant today.

\section{The Bateson-Saunders Equilibrium}

In a landmark report to the Royal Society, Bateson and Saunders (1902) present some of their own genetical findings, and discuss the evolutionary implications of Mendelism. In regard to a population with recognizable Mendelian characters, they suggest:

It will be of great interest to study the statistics of such a population in nature. If the degree of dominance can be experimentally determined, or the heterozygote recognised, and we can suppose that all forms mate together with equal freedom and fertility, and that there is no natural selection in respect of the allelomorphs, it 
should be possible to predict the proportions of the several components of the population with some accuracy. Conversely, departures from the calculated result would then throw no little light on the influence of disturbing factors, selection, and the like. (p. 131)

This shows a concern for what is now called "population genetics," and more specifically, it is a concise verbal description of what is now called the "Hardy-Weinberg Equilibrium," a foundational model in population genetics (Provine, 1971, pp. 131-135) that continues to play a role in research (e.g., a search of PubMed yields over 3000 articles that invoked "Hardy-Weinberg" in the past 10 years). Precisely as advocated by Bateson and Saunders, the Hardy-Weinberg Equilibrium plays the role of a zero-force model (i.e., a system at rest, with no "disturbing factors") in understanding population-genetic causation: deviations from equilibrium indicate the perturbing effect of some factor or force.

Bateson and Saunders did not solve the mathematics of the HardyWeinberg Equilibrium, but rather conceptualized the zero-force model and foresaw its utility. It was Punnett who brought about the mathematical solution by presenting the problem to Hardy, his Cambridge colleague (Provine, 1971, p. 134). Punnett referenced Hardy's 1908 solution in his 1911 textbook (p. 148) and later applied it to the analysis of butterfly mimicry (Punnett, 1913, 1915).

\section{Discrete Basis of Continuous Variation}

Bateson immediately understood that explaining the heritability of a quantitative traits such as stature (i.e., traits that appear to give a smooth distribution) would require a multifactorial Mendelian view, expressing this idea both with Saunders (1902, p. 155), and in his defense of Mendelism (1902):

In the case of a population presenting continuous variation in regard to say, stature, it is easy to see how purity of the gametes in respect of any intensities of that character might not in ordinary circumstances be capable of detection. There are doubtless more than two pure gametic forms of this character, but there may quite conceivably be six or eight. When it is remembered that each heterozygous combination of any two may have its own appropriate stature, and that such a character is distinctly dependent on external conditions, the mere fact that the observed curves of stature give 'chance distributions' is not surprising and may still be 
compatible with purity of gametes in respect of certain pure types. (p. 31)

Thus Bateson argues that the standard bell-shaped "chance distribution" may be compatible with Mendelism because it can result by the combined effects of a multiplicity of Mendelian differences (each with 2 homozygotes and 1 heterozygote) and non-heritable variation due to "external conditions."

By 1903, Johannsen had shown that, from a general population showing a bell curve of variation, he could isolate individual lines that each showed a different bell curve of variation that remained constant. Morgan (1916, p. 158) reproduced figures from Johannsen's work (Figure 1), arguing that the variations in a pure line are extrinsic to the germ plasm, that populations are heterogeneous mixtures of types, and that selection may move the distribution of a heterogeneous population, a process that is haphazard - because the size of an individual bean reflects haphazard environmental effects, not just genetics - yet "almost certain" in the long run (p. 160).

In other words, Bateson, Johannsen, Morgan, and Punnett (see below) allowed that the characteristic bell-shaped distribution of a quantitatively varying character may reflect either (1) ephemeral environmental variations of a single underlying hereditary type, or (2) the overlaying of environmental variation on a mixture of types, which is how such distributions are understood today (with roughly equal contributions of genetic and environmental variance, as in Mousseau and Roff, 1987). They did so prior to the work of Fisher (1918) that attributes the variability of quantitative traits to (3) heritable variation almost exclusively (see Fisher, 1918, pp. 423-427).

\section{Selection on a Quantitative Character}

In 1904, Bateson suggested that "when the unit of segregation is small, something mistakably like continuous Evolution must surely exist" (quoted by Provine, 1971, p. 69). Johannsen had created a mixed population of known pure-breeding lines, using this in 1903 to show that selection could sort out varieties, while not fundamentally changing them. Data from some of Johannsen's experiments are used in contemporary textbooks to illustrate principles of population genetics (e.g., Hartl and Clark, 1997, p. 409).

To explain how smooth change in a quantitative character can occur under selection, Punnett (1911) constructs a hypothetical example with three imaginary non-mixing strains $\mathrm{A}, \mathrm{B}$, and $\mathrm{C}$, differing in the weight 


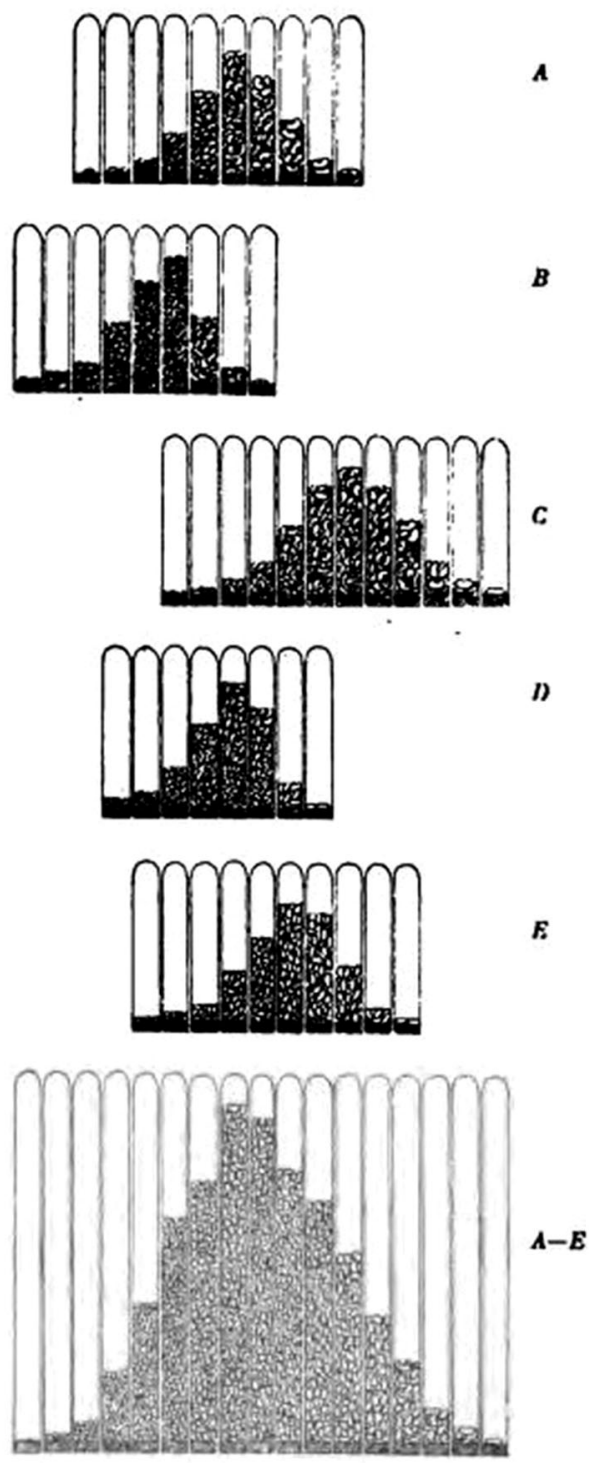

Figure 1. Johannsen's decomposition experiment as shown by Morgan (1916, p. 158). Morgan's caption reads "Pure lines of beans. The lower figure gives the general population, the upper figures give the pure lines within the population"

of seeds (Figure 2). He explains that "a seed that weighs 12 grains may belong to any of these three strains. It may be an average seed of $\mathrm{B}$, or a rather large seed of $A$, or a rather small seed of C" (p. 162). He then theorizes about the effect of selecting seed on the basis of size: 
On this view we can understand why selection of the largest seed raises the average weight in the next generation. We are picking out more of $\mathrm{C}$ and less of $\mathrm{A}$ and $\mathrm{B}$, and as this process is repeated the proportion of $\mathrm{C}$ gradually increases and we get the appearance of selection acting on a continuously varying homogenous material and producing a permanent effect (pp. 162-163)

By contrast, in Darwin's view, the superficial appearance that the whole population has shifted continuously and homogeneously reflects an underlying reality in which hereditary substances shift continuously and then are blended into homogeneity. There is no apparent limit to this process, because in Darwin's theory, indefinite variations ("everywhere present") continue to appear. Thus Morgan remarked that, under the Darwinian view, one ought to be able to breed "pigeons with legs five metres long" (Morgan 1903, p. 103).

The Mendelian alternative differs in that (1) selection of a phenotypic range implicates hereditary factors only indirectly and probabilistically; (2) the end result is a not a new complement of hereditary factors, but a mixture of old components in new proportions; and (3) without new mutations, the population may not transcend the limits inherent in the original population.

The last of these claims is either wrong or misleading. Whether or not selection can produce a pigeon with legs $5 \mathrm{~m}$ long, selective breeding from a population of individuals whose highest phenotypic value is $T_{\max }$ can generate a variety whose highest value exceeds $T_{\max }$ even if selection is merely sorting out pre-existing varieties, as in Punnett's example. If recombination is allowed, then the selected population can have a mean

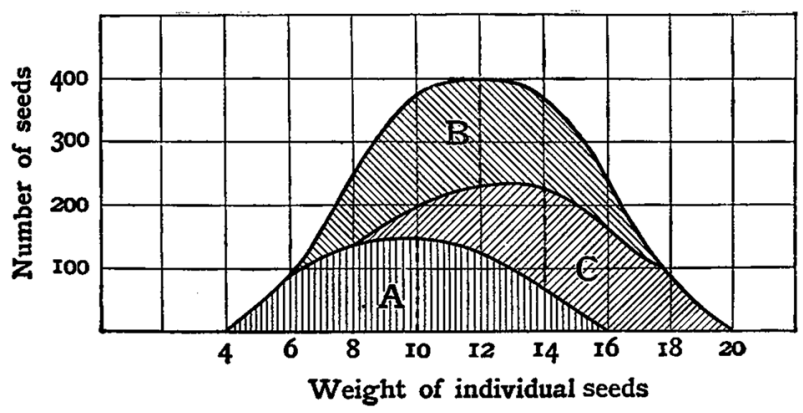

Figure 2. Punnett's illustration of the distribution of weights of individuals of three different classes in a mixed population (inspired by Johannsen's experiments), used in a didactic explanation of selection on a smoothly varying trait (1911, p. 161). See text for explanation. Punnett's original caption reads "Curves to illustrate the conception of pure lines in a population" 
(or even a minimum) that exceeds $\mathrm{T}_{\max }$. The idea that the effects of selection are limited by the initial population is valid only in the sense that it is limited by its hidden (abstract) genetic potential, not by the actually observed phenotypic range. Contemporary students of population genetics often make the latter mistake, according to Hartl and Clark (1997, p. 413).

Note that Punnett's example of sorting out existing varieties from a superficially smooth distribution, like Johannsen's experiments, falls short of the Modern Synthesis view, because it does not invoke recombination to allow "selection," without new mutations, to shift the population well beyond the limits of the starting population, as discussed further below (see Discussion). Punnett's textbook repeatedly invokes the idea of new combinations of genes as a basis for evolution or practical breeding (e.g., Punnett, 1911, pp. 144, 156), thus recombination is a part of his theory of evolution. However, in 1911 he evidently did not believe that recombination is essential for illustrating how smooth change is possible in a Mendelian world.

\section{The Allelic Selection Model}

Punnett's Mimicry in Butterflies (1915) features a table of calculated values showing the rise in frequency of a Mendelian variant under the influence of selection. He had taken this problem to his colleague Hardy, who passed it to H.T.J. Norton, who shared his results with Punnett but did not publish them for over a decade (Norton 1928). Provine (1971, pp. 137-139), who refers to Norton's model as "the perfect complement to Morgan's theory of evolution by single gene replacement," notes that it was the stimulus for Haldane's famous series of allelic selection models in the 1920s - the work that earned Haldane his status as a founder of population genetics. Today, models of allelic selection, showing the rise of a rare favored allele, are a staple of evolution textbooks (e.g., Freeman and Herron 1998, Figure 5.6). Punnett invoked both the allelic selection model and the Hardy-Weinberg equilibrium in his arguments on butterfly mimicry, and though his assumptions were naïve, he specifically invoked the 
allelic selection model as though it proved that selection can act swiftly. ${ }^{13}$

\section{Saltation by Mutation}

The saltationism of de Vries and the Mendelians (described above) entails (1) a rejection of Darwin's abstract infinitesimalism, and an embrace of the contrary of allowing non-infinitesimal effects or jumps; (2) a rejection of the view that the definiteness (regularity, symmetry, etc.) of an organic form can emerge only via many variations gathered under the shaping influence of selection, and conversely, as an endorsement of the notion that internal generative processes can give rise to such definiteness in a novel form; (3) an empirical argument (or a research program) that aims to establish a prima facie case for saltation based on the similarity of mutant forms to natural forms. All three aspects are found in contemporary evolutionary biology.

Orr's (2005) authoritative review addresses the "rise and fall" of the "micromutationist" view of the Modern Synthesis, concluding that large-effect variations commonly play a role in species divergence, and characterizing infinitesimalism as "little more than a mathematical convenience" (see also the reference of Chouard 2010 to a discarded "gradualist dogma"). Orr's complaint that Fisher's infinitesimal model stifled research for decades by "assuming away" the problem recalls Bateson's sarcastic critique a century earlier, which Orr actually quotes:

By suggesting that the steps through which an adaptive mechanism arose were indefinite and insensible, all further trouble is spared. While it could be said that species arise by an insensible and imperceptible process of variation, there was clearly no use in tiring ourselves by trying to perceive that process. (Bateson 1909a)

Several recent books on molecular evolution emphasize the well known role of non-infinitesimal mutations such as gene duplications, fusions, lateral gene transfers, and genome doublings (Koonin, 2011; Nei, 2013; Shapiro, 2011). Interestingly, in response to the claim by Shapiro (2011)

13 According to Punnett's reasoning, because selection acts so swiftly, a polymorphism for mimicry would not persist for a long time if the mimics are beneficial, therefore the persistence of a polymorphism is evidence against mimicry as a benefit (the logic of this argument was undermined later by the recognition that a polymorphism can be maintained indefinitely by balancing selection). He further argues that the three morphs (one non-mimetic) in an island population of $P$. polytes are in Hardy-Weinberg equilibrium, concluding that selection must not be acting and that, therefore, the butterflies are not truly mimetic (Punnett 1913, 1915). 
that molecular saltations weigh against Darwinism, Dean (2012) replies that the charge is "patently unfair" because "today's Darwinists accept Huxley's criticism," i.e., they have abandoned natura non facit saltum.

The remaining aspects of saltationism, i.e., (2) and (3) above, are manifested in the contemporary field of "evo-devo". A major project of contemporary evo-devo is to develop a substantive theory of the generation of phenotypic variation by mutation and development (e.g., Kirschner and Gerhart, 2005; Hendrikse et al., 2007), carrying forward Bateson's (1894) vision. The premise of this project is that developmental changes, by giving shape to phenotypic variation, give shape to evolutionary change. Evo-devo-ists invoke development as a generative process responsible for the definiteness of variant phenotypes (e.g., Arthur, 2000), and they embrace a research program that (among other pursuits) attempts to understand evolved differences in terms of the distinctive phenotypic effects of individual mutations (e.g., Stern, 2000).

\section{Selection as a Stochastic Sieve for Mutations}

According to Gayon's (1998) thesis noted earlier, the new genetical conception of selection as a frequency-shifting force is used to rationalize a more Darwinian conception of selection as a shape-shifting force. However, neither of these conceptions of selection as a smooth shifter captures the way in which Morgan, Punnett and de Vries often evoked evolution as a stochastic process of the acceptance of lucky mutations, with selection in the role of a filter or sieve that modulates the chances of success. For instance, Morgan writes (1916; see also Punnett, 1911, p. 142):

If through a mutation a character appears that is neither advantageous nor disadvantageous, but indifferent, the chance that it may become established in the race is extremely small, although by good luck such a thing may occur rarely. It makes no difference whether the character in question is a dominant or a recessive one, the chance of its becoming established is exactly the same. If through a mutation a character appears that has an injurious effect, however slight this may be, it has practically no chance of becoming established.

If through a mutation a character appears that has a beneficial influence on the individual, the chance that the individual will survive is increased, not only for itself, but for all of its descendants that come to inherit this character. (187-189) 
Morgan's intuitive concept of the probability of "becoming established" corresponds to the population-genetics concept of a "probability of fixation" for a new mutation, and his remarks on this topic (including the irrelevance of dominance or recessivity for the fixation of a neutral allele) are consistent with the mathematical theory developed several years later by Haldane and Fisher (Stoltzfus, 2006).

Though the architects of the Modern Synthesis rejected this "lucky mutant" view (e.g., Mayr, 1963, pp. 101, 613), it returned when molecular evolutionists re-conceptualized evolutionary change in terms of mutations that selection either "accepts" or "rejects" (e.g., Eck and Dayhoff, 1966, pp. 161, 200; King, 1971), acting as the "editor", not the "composer", of the genetic message (King and Jukes, 1969). Molecular evolutionists developed a mathematical model that links the rate of evolutionary change directly to the rate of mutational origin of new alleles, and to their probability of fixation (King and Jukes, 1969; Kimura and Maruyama, 1969). Today these 2-step origin-fixation models are an important branch of theoretical evolutionary genetics with a variety of applications (McCandlish and Stoltzfus, 2014), including approaches to testing hypotheses about mutational or selective causes of evolutionary biases (Streisfeld and Rausher, 2011), and models for exploring the dynamics of adaptation (the "mutational landscape" model of Orr, 2002). The concept that evolutionary change begins with a new mutation, rather than with selection shifting the frequencies of pre-existing alleles ("standing variation") is "clearly the ruling paradigm" in molecular studies, according to Hermisson and Pennings (2005; see also Barrett and Schluter, 2008, p. 39).

\section{Non-Random Mutation in Parallelism and Directionality}

The Mendelian-Mutationist view suggested the possibility that internal factors could influence the course of evolution by determining that some kinds of mutations appear more often than others. Both Morgan (1910) and Bateson (1909a) considered the possibility that the biased generation of mutations might account for directions or patterns. ${ }^{14}$ Morgan proposed that mutation in a particular direction might be more likely, ex posteriori, after an initial step that happens to be beneficial: "After the first step, which was undirected, i.e., not purposeful, the subsequent

${ }^{14}$ Whereas de Vries (by contrast) held that mutations happen "in all directions" (e.g., de Vries 1905, pp. 570, 719), his results indicated, that the same idiosyncratic mutations occur repeatedly, a contradiction pointed out by Metcalf (1905). 
events are rendered more probable; for the dice are loaded" (Morgan, 1910, p. 208).

A more modest version of this idea was that the individual steps of evolution, as accepted mutations, have directions that reflect the idiosyncratic character of the mutation. It follows that parallel mutations might account for parallel evolutionary changes: non-randomness in mutation increases the chance of parallelism relative to the case in which all possibilities have the same a priori likelihood. Fisher's contrary assumption that mutation is random, and cannot be a source of direction in evolution, was criticized directly by Punnett (1930) and Shull (1935), who said that "It strains one's faith in the laws of chance to imagine that identical changes should crop out again and again if the possibilities are endless and the probabilities equal" (p. 448).

Thus Morgan (1923) highlighted "recurrent and parallel mutants" as "one of the most interesting discoveries in recent genetic work", citing cases in which similar mutations happen in closely related species. Punnett also had argued that color variations in mice and rabbits were the result of the same genetic factors, and that parallel variation could account for mimicry (Punnett, 1913). This idea that parallel variations may lead to parallel patterns of species differences was taken to great lengths by the renowned Russian geneticist Vavilov (1922), who had studied genetics in England with Bateson, Biffen and Punnett (Adams, 1980).

In Bowler's historical analysis, the hypothesis of biased variation as a source of direction is taken to reflect the "anti-Darwinian" inclinations of Bateson and Morgan (Bowler, 1988, p. 121). Today, the idea that developmental biases on the production of variation shape evolution is a major theme of "evo-devo" (Maynard Smith et al., 1985; Arthur, 2004). The similar idea that mutation biases shape genomes has been common in molecular evolution for many years (see Stoltzfus and Yampolsky, 2009). Contemporary evolutionists clearly have sought and found evidence of parallel mutational changes, either directly at the molecular level (Rogozin et al., 2008; Cunningham et al., 1997; Macey et al., 1997; Hancock and Vogler, 2000) or via the analysis of parallel evolution (Martin and Orgogozo, 2013; Denver et al., 2010; Christin et al., 2010; Wood et al., 2005).

\section{Speciation and Incompatibility}

Bateson is quoted approvingly by Dobzhansky (1937) for his statement that "though we cannot strictly define species, they have yet properties which varieties have not, and... the distinction is not merely a matter of degree." Unlike Darwin, but like Dobzhansky (as well as earlier 
thinkers such as Huxley and Romanes), the early geneticists tended to believe that reproductive incompatibilities were "the true criterion of what constitutes a species" (e.g., Punnett, p. 151). With the Modern Synthesis, the "biological species concept," by which a species is defined in terms of the ability of organisms to interbreed, became the prevailing view (Mallet, 2013).

Just as for contemporary researchers (Coyne and Orr, 2004), the early geneticists considered both Mendelian and non-Mendelian causes of incompatibility. A Mendelian idea suggested by Bateson (1909a) is that, if an incompatibility is to arise by individual Mendelian changes in a sexual population, it cannot involve just one change, otherwise the initial mutant would be isolated from its breeding partners. However, changes in two "complementary factors" that interact in some way could result in an incompatibility. This idea is sometimes referred to as the "Bateson-Dobzhansky-Muller" model (Orr, 1996), and remains a central idea in contemporary thinking about the genetics of speciation (Coyne and Orr, 2004).

The early geneticists also proposed non-Mendelian mechanisms. Bateson and Johannsen both believed that the operation of Mendelian factors was superimposed on some more fundamental basis or residue that underlies some kinds of incompatibility (Cock and Forsdyke, 2008). However, de Vries's ideas have been the most important non-Mendelian ideas on speciation. As noted earlier, his Oenothera mutants were shown to arise, via several different types of complex changes in chromosomes, from an original polyploid hybrid, rather than via ordinary gene mutation (Sturtevant, 2001). Nevertheless, it is now known that most plant species are ancestrally polyploid, and that the types of changes studied by de Vries are quantitatively important in plant speciation (Nei and Nozawa, 2011).

\section{Discussion}

Our deliberate aim has been to provide an internalist rationale for the evolutionary views of early geneticists. We have focused on Bateson, de Vries, Morgan and Punnett as the early geneticists who most influenced evolutionary discourse during the first 2 decades of the twentieth century. In the sections that follow, we address some differences between our analysis and the classical view, and some of the questions that arise from these differences, regarding fluctuation, the "missing piece" theory, and the curious case of Hugo de Vries. 


\section{Contextualizing Fluctuation and Selection}

The nineteenth-century view of "soft inheritance" is intrinsic to at least two of the three major means of evolutionary modification invoked by Charles Darwin - direct action of the environment, and effects of use and disuse (Lamarckism). According to early geneticists, the same error also pervades Darwin's construction of "natural selection." Morgan, de Vries, Bateson and Punnett all rejected Darwin's original theory because they associated it fatally with the mistaken belief that environmentstimulated phenotypic fluctuations could be the basis of significant evolutionary changes. That is, Darwin's claims for "natural selection" were understood to rely intrinsically on exactly the kind of environmental variation that Johannsen isolated by studying fluctuations in a pure line, thus the failure of selection in a pure line showed precisely that Darwin's view could not be correct.

This issue does not appear overtly in the classical view. When early geneticists point to a mechanistic distinction between fluctuation and mutation, classical authors treat this as a matter of size (small vs. large), rather than a reference to an underlying mechanistic difference that is correlated loosely with size (e.g., Mayr, 1988, p. 527; Allen, 1980, pp. 367-370). Mayr believed that "the components into which Darwin's individual variation can be dissected show the same hard inheritance as sports or conspicuous mutations" (Mayr, 1980, p. 19). This failure to contextualize the geneticists' critique leads to several errors, including the notion that Johannsen's results proved nothing, but merely gave credulous anti-Darwinians a reason to reject selection prematurely. For instance, Ford (1938, p. 43) states that the outcome of Johannsen's experiments was "logically evident", and proved nothing - which is true only if one already has (1) accepted Mendelism and (2) edited Darwin's theory. Likewise, Provine (1971) suggests that the "pure line" theory (that selection cannot be effective in a line purified by inbreeding) is based on "circular reasoning" (p. 108). Sapp (2003) argues that Johannsen's experiments were "faulty" because he "mistook an artificial population for a natural one" (p. 145). Apparently, once Mendelism was firmly established, the nineteenth-century theory of evolution-by-fluctuation largely went down the memory hole (with exceptions such as Roll-Hansen, 1989), and the incompatibility perceived a century ago between Darwin's theory and Johannsen's results became an enigma to be addressed by appeal to "anti-Darwinian prejudice" (Allen, 1980, p. 368) and the like.

Nevertheless, this issue emerges in many sources - not only the writings of the early Mendelians, but of their opponents, and even in classical histories. Defending Darwin at a time when Mendelism could be doubted, 
Cook (1908) argues that Mendel should have read Darwin more carefully; that Darwin understood non-blending inheritance better than Mendel; that Darwin correctly judged the theories of mutation and non-blending inheritance to be incompatible with gradual evolution; and that Darwin correctly concluded that evolution must have a different basis, in the inheritance and blending of ordinary variations. In Provine's (1971) account, the conflict between Darwinian evolution-by-fluctuation and Mendelian genetics is revealed in passing at least three times, ${ }^{15}$ most remarkably when Provine, noting that Pearson refused to consider (for his journal Biometrika) the manuscript that became Fisher's famous 1918 paper, reveals that "Pearson claimed, and Darwin would probably have agreed, that the continuous variations in a pure line were heritable and that continued selection in a pure line should be effective" (p. 143).

The discovery that the non-heritability of environmental fluctuations was a crucial issue in the debate over evolution raises interesting questions about the extent to which scientific and historiographic views have been shaped by interpretations of Darwin. ${ }^{16}$ Clearly, the Modern Syn-

15 The other two instances are as follows. Provine notes on p. 65 that de Vries's pangenesis theory, by eliminating any path for variations to flow backwards from the body to the germ-plasm, eliminates Darwin's "major mechanism for the production of individual differences, the raw material for selection," i.e., Provine construes somatic sources of variation as "major" in Darwin's view. Darwinian evolution-by-fluctuation also intrudes when Provine cites a famous and long-running dispute over the significance of Castle's selection experiments with the hooded rat (pp. 113 to 129). Castle argued that his results indicated a role for continuous fluctuations in the potency of factors, while other geneticists, including members of the Morgan lab, argued for a strictly Mendelian explanation. Oddly, Provine's narrative (also Gayon, pp. 309 to 311) presents Castle as a bellwether beset by obstructionists who doubt the power of selection, yet it was Castle - not the other geneticists - who doubted the sufficiency of the selection-Mendelism combination, until forced to concede in 1919.

${ }^{16}$ Note that the geneticists' interpretation is defensible, not merely as the proper historical context for understanding their criticism of Darwin, but also as a matter of how to understand Darwin's true intent. Darwin believed that all variation is triggered by conditions (Winther 2000), stating that "if it were possible to expose all the individuals of a species during many generations to absolutely uniform conditions of life, there would be no variability" (Darwin 1868, Ch. 22). As Gayon (1998; see also Beatty 2010) has noted, Darwin deliberately chose to reject hard inheritance of individual variants as the solution to Fleeming Jenkin's criticism. Darwin staked his theory on the blending of masses of infinitesimal variations, and this was neither a capitulation nor a reversal, but the solidification and clarification of Darwin's long-standing preference. Darwin's description of indefinite variability or ordinary variation - indefinite, arising en masse every generation, stimulated by conditions of life (increasing under more extreme conditions), and appearing to blend - fits much more closely with phenotypic fluctuations due to conditions, than with the emergence of new genetic variation by mutation or recombination. 
thesis established the compatibility of Darwinism and Mendelism, but this was accomplished partly, and perhaps largely, by reinterpreting Darwin to make room for Mendelism. The early geneticists reconceptualized "natural selection" (Gayon, 1998), yet how did this new idea of selection come to be attributed to Darwin instead of de Vries, Bateson and Morgan? How and when did Darwin's followers decide that it was all right to ignore - and even to deny (as in the statement of Mayr quoted above) - Darwin's patently non-Mendelian views? Perhaps a "Darwinian" synthesis with Mendelism had to await the passing of a generation of scientists that defended (Pearson, Cook, Wallace) or criticized (Morgan, Punnett, Bateson) Darwin's theory in its original non-Mendelian form.

Finally, we note an interesting difference with Gayon, who argues that "the decline of Darwinism was virtually always attributed to the experimental refutation of the hypothesis of 'natural selection' in the highly restrictive sense that Darwin had intended" (Gayon, 1998, p. 2). This might suggest that Gayon's interpretation aligns closely with our focus here on the geneticists' critique of fluctuation. Actually, although Gayon notes this critique, he suggests that it "turned out to be a fiction" (p. 309), and instead locates the conflict between Darwinism and genetics entirely in Darwin's reliance on blending. Ultimately, he treats the mutationists' critique of evolution-by-fluctuation as though it were a premature rejection of selection on small variations (e.g., pp. 103-104). One might study the works of early geneticists in greater breadth and depth, in order to understand which specific results were thought to refute Darwin's theory, and whether they were understood to refute (1) blending, (2) the heritability of fluctuations, or (3) the mode of evolution that combines the two.

\section{The Influence and Non-Influence of de Vries}

Though the classical narrative makes Hugo de Vries the progenitor of a widely popular "mutationist" school, ${ }^{17}$ we see few indications that de

17 Sources that invoke the popularity of de Vries (e.g., Richmond 2006; Theunissen 1994; MacKenzie 1981, p. 258) invariably cite Allen (1969). Perhaps de Vries's distinctive views - progressive mutations, partially heritable fluctuations, rare mutation periods, elementary species - were widely popular, but Allen's analysis does not establish this. Allen's claim of a "large number of workers" who "supported the theory with varying degrees of enthusiasm" refers to a footnote that lists exactly 14 scientists (p. 66). After explaining how a few of these scientists, such as Morgan, were excited by the prospect of finding mutations, Allen goes on to list 7 opponents. He does not seem to consider the possibility that "mutation" might be a very general concept welcomed by scientists who did not accept de Vries's special theories. For instance, he cites Metcalf as a "follower" (p. 78), but an examination of the cited work (Metcalf 1905) reveals no particular allegiance to de Vries's special views. 
Vries's specialized ideas influenced leading geneticists. They embraced some of his terminology, but not its meaning. For leading geneticists, the significance of de Vries's work was that it finally laid to rest any doubts that, in a state of nature, definitely heritable types could arise suddenly and be propagated indefinitely.

Though this does not directly contradict the widespread belief that de Vries's views were widely popular, it raises questions about the nature and extent of this alleged popularity. Clearly the idea of mutation was influential, as was the idea of dramatic or monstrous mutations (e.g., Hoquet, 2010; Richmond, 2010). Kingsland (1991) argues that the popularity of de Vries's view had much to do with the way that it promised to empower plant breeders to improve domestic crops and to contribute to debates on evolution. Which scientific communities were the most influenced by de Vries? How much did the misapprehension of de Vries's views reflect the complexity and disorganization of his written works, which have taken many years for historians to decipher even partially? ${ }^{18}$ Certainly it would be possible to study how de Vries's views were received by the complete set of geneticists active in the first decade of the twentieth century, following Buttolph's (2008) study.

\section{The Missing Pieces Theory}

The classical narrative denies a theoretical clash between Darwinism and Mendelism, and articulates their relationship in terms of the "missing piece" theory, in which Mendelism is the "perfect complement" to Darwin (Provine, 1971, p. 130), and the decades-long failure of scientists to perceive this perfect fit is an "inexplicable embarrassment" (Hull, 1985). The popularity of this view is indicated by Bowler's (1988) complaint that "the Darwin industry has followed Fisher's assumption that genetics merely fills in the gaps in Darwin's thinking" (p. 130).

The first problem with the missing pieces theory, pointed out by Bowler, is that the pieces are not missing. Darwin promulgated both (1) a phenomenological theory of variation (i.e., empirical or descriptive "laws"), and (2) a mechanistic theory of variation (pangenesis) to account for these laws via reproductive physiology (see Winther, 2000). Both were wrong. The problem of heredity was not "left unsolved" by Darwin (Allen, 1980, p. 361), but solved incorrectly. Fisher refers to that which is absent from a "structure first erected by Darwin" (Fisher, 1930, p. ix), as though this "structure" were a Platonic

18 Theunissen (1994) writes in regard to de Vries's magnum opus, "Considering the book's excessive length and apparently chaotic organization it is perhaps not too surprising that a complete analysis of the work has never been attempted" (p. 239). Perhaps de Vries's scientific peers likewise never fully understood his complex thinking. 
form seen only partly by Darwin, and recognized fully by Fisher. In reality, Fisher has deleted some of Darwin's deliberate choices. Thus, one must reject the idea of "missing" pieces: at best, this is a theory of substituted pieces.

How does this substitution change Darwin's theory? If we are to allow Fisher to re-engineer the inner workings of Darwin's theory, the revised theory must generate the same kinds of hypotheses, predictions and explanations as the original - otherwise we have no basis for representing it as the same theory. In this regard, it is important to emphasize that Mendelian evolutionary genetics does not guarantee Darwinian behavior. Mendelian evolutionary genetics clearly allows neutral evolution (Kimura, 1983), changes that depend on individual events of mutation (Blount et al., 2008), and other non-Darwinian behavior mentioned earlier, including non-gradual changes, and parallelisms or trends due to biases in variation.

Thus, the "perfect complement" to Darwin's thinking cannot be Mendelism per se, but could be some version of Mendelism restricted with auxiliary theories or assumptions to reject alternatives and ensure compatibility. The nature of these auxiliary theories is evident in Provine's analysis. The Mendelians accepted a non-exclusive role for small variations and smooth change, but this does not qualify them as Darwinians. Instead, the decisive issue is the capacity of "selection" to shift the mean value of a trait beyond the observed range of the initial population, without new mutations, relying instead on recombination of abundant variation present in the initial population. ${ }^{19}$ Provine calls this capacity "the effectiveness of selection." In his narrative, the historic battle to establish the foundations of modern neo-Darwinism (at least, among geneticists) is won by about 1919 when key geneticists accept "the effectiveness of selection" as the sine qua non of evolution. ${ }^{20}$

19 Note that the "effectiveness of selection" is based on recombination. In this context, "recombination" is not limited to recombining genes on homologous chromosomes by crossing over, but implicates any process that brings together new combinations, including sexual mixis and re-assortment of non-homologous chromosomes.

${ }^{20}$ For instance, Provine's position is evident in his treatment of East. He quotes East's 1910 description of a process of sorting out pre-existing varieties and concludes that East had "not discovered the full implications of recombination for evolutionary adaptation... East was unaware of the immense possibility for genetic recombination to occur within the population and was in substantial agreement with Johannsen, Jennings and Pearl" (Provine 1971, p. 119). On this basis, Provine puts East (as of 1910) in the camp of Johannsen and the non-Darwinian "pure-linists" who have not achieved a true synthesis. Provine's interpretation of Johannsen is disputed by Roll-Hansen (1980), on the grounds that Johannsen included recombination in his understanding of evolutionary change. Earlier, we made the same point about Punnett, who clearly included recombination in his evolutionary thinking. 
That is, the justification of Darwinism depends on the notion that selection can create new forms without mutation, which Darwin, Pearson, and Castle (arguably, for a time) had believed for the wrong reasons. The new Mendelian version of this justification hinges on the superficial appearance that selection creates new forms without mutation, even though this involves a conceptual sleight-of-hand that bestows credit on "selection" for the new combinations accomplished by unseen events of recombination (as pointed out by Nei, 2013, p. 38), while avoiding the question of how mutations become involved in evolution (as, presumably, they must).

Nevertheless, according to the classical view of Provine, this is the essence of the Modern Synthesis as a theory of evolutionary genetics: if we replace the blending and indefinite variability (in Darwin's theory) with Fisherian change given the availability of abundant multifactorial variation created by recombination, we get a quasi-Darwinian genetical view that explains evolution via "natural selection." Gayon does not accept the missing piece theory, but invokes precisely the same auxiliary theories as Provine to explain how a Darwinian mode of evolution is "rehabilitated" in a Mendelian world. ${ }^{21}$

Given that it is possible to formulate a Mendelian theory of evolution with Darwinesque behavior, the remaining issue is whether scientists understand the resulting theory to be sufficient. Clearly they do not. Though quantitative genetics - the branch of theory that, following Fisher (1918), depicts smooth change based on abundant infinitesimal variation - is clearly an important topic in evolution, it is neither the foundation, nor the acme, nor the majority of evolutionary theory: it does not dominate textbooks of evolutionary genetics, but is one of a handful of separate topics (e.g., see Hartl and Clark, 1997; Gillespie, 1998). Presumably no biologist today believes that this branch is a sufficient theory of evolution: it would be rejected for its failure to accommodate various non-Darwinian behavior noted earlier, e.g., evolution dependent on a single lucky mutation.

In short, if we treat the rehabilitation of Darwin's theory narrowly as the Mendelian theory of quantitative evolutionary genetics, then it clearly is not the foundation of evolutionary biology, but a sub-theory;

${ }^{21}$ In Gayon's account, it is not a Darwinian theory or mechanism that is "rehabilitated," but a distinctly Darwinian conception or principle of selection as a shapeshifting force that is, in effect, reduced to a consequence of Fisherian quantitative genetics. Gayon clearly rejects the "missing piece" and, accordingly, the idea that Darwin's theory was restored in an intact form. Instead, the synthesis with Mendelism created a hybrid view "profoundly reorganized in its internal theoretical structure" (p. 13), including a "subtle but decisive modification of the principle of selection" (p. 253). 
if we treat this fusion broadly as a synthesis of genetics, selection and mutation, then it is not always Darwinian in behavior, and it is not the work of the Modern Synthesis, but of the early Mendelians.

Thus, the paradoxical "missing piece" argument is problematic as history, as philosophy, and as science. The early decades of the twentieth century become an inexplicable embarrassment in the classical view, precisely because of the premise that genetics is the perfect complement to Darwinism. If we reject this same premise, a different picture emerges. Johannsen's experiments were profoundly influential, not because scientists of his time were easily confused and prone to stampede, but because he rigorously tested and rejected a major theory, while demonstrating a successful alternative (Roll-Hansen, 1989). Pearson and his biometrical school resisted Mendelism, not because they disliked Mendelians personally and opposed manipulative experiments, but because they were committed to a non-Mendelian view of evolution with a strong claim to being the correct interpretation of Darwin's theory (see also Roll-Hansen 1980). The Modern Synthesis was delayed because both partners in the marriage of Darwinism and genetics had to be dragged, kicking and screaming, into the union, which combined an unjustifiably loose interpretation of Darwin with an unjustifiably narrow and speculative view of population genetics.

\section{The Non-Darwinian Synthesis}

Some recent work identifies a scourge of "Synthesis Historiography" (Amundson, 2005), and a desire to escape from triumphalist or selfserving narratives emanating from the architects of the Modern Synthesis (e.g., Mayr's Essentialism Story). Apropos, the parochial nature of the "missing piece" theory is revealed strikingly in Fisher's 1930 critique of Bateson, which is the origin of the theory, according to Bowler (1988, p. 130) or Peterson (2008, p. 271). Actually, Fisher is not the original source. He had asked for an opinion on Bateson from his mentor Major Leonard Darwin (to whom Fisher would dedicate his 1930 book), and the latter obliged with the following scathing account (see Bennett, 1983, pp. 95-96):

In the future the great merit of Mendelism will be seen to rest on the proof that the ingredients of germ plasm on which heredity depends are located in pairs in each organism, one of each pair selected by chance disappearing at each sexual union.... The merit for this discovery must mainly rest with Mendel, whilst among our countrymen, Bateson played the leading part in its rediscovery. 
Unfortunately he was unable to grasp the mathematical and statistical aspects of biology, and from this and other causes, he was not only incapable of framing an evolutionary theory himself, but entirely failed to see how Mendelism supplied the missing parts of the structure first erected by Darwin. Nothing but harm can come from following Bateson in regard to evolution theory, though his name will come to be honoured for his pioneer work in Mendelism when what he failed to do as regards theory has been accomplished.

Leonard Darwin admitted that he was not familiar with Bateson's actual work, and wrote "having written it, I daresay I should tear it up, and advise you to do ditto." Fisher ignored this advice and used a revised version of the text above (Fisher, 1930, p. ix). In other words, the first draft of the classical view, complete with the missing pieces theory (and the meme of the Mendelians' cognitive deficiency), was written by Charles Darwin's son, and published by the premier architect of neo-Darwinian gradualism, in a willful conspiracy to remain ignorant of what Bateson actually believed.

The classical view nonetheless serves a useful purpose as a depiction of the main line of development of evolutionary thought, as it appeared to followers of Darwin 50 years ago. For them, the view promoted by Fisher, Dobzhansky, Mayr, et al. is the correct and decisive synthesis of genetics and evolution: the integration of Mendelism into evolutionary theory was not complete until it was possible to argue that, in a Mendelian world, (1) a creative Darwinian mode of "natural selection" is possible, by which the struggle for life shapes phenotypes by gathering masses of individually minor variations, and (2) all alternatives including saltationism and the "lucky mutant" view - must be rejected, as per Provine's $(1978,1986)$ revisionary view of the Modern Synthesis as a "constriction" (similar to the "restriction" view of Gould, 2002, pp. 505-518). That is, the premise of the Modern Synthesis, and of the classical historiographic view, is that genetics justifies Darwin's view and undermines all alternatives, precisely as argued in the opening pages of Fisher (1930).

The scientific reasoning underlying this premise, most of which has been discussed, is as follows. Mendelism rules out Lamarckism and direct effects. Orthogenesis is alleged to have no valid mechanism. Fisherian quantitative genetics rationalizes a Darwinian mode of evolution, but does not exclude alternatives. The keystone is the multifactorial view, which later developed into a picturesque "gene pool": natural populations "maintain" abundant variation, remixing it via recombination every generation, so that selection never waits for a new 
mutation, but finds abundant variation ready at hand to create a smooth adaptive response to new conditions (see Stoltzfus, 2006; McCandlish and Stoltzfus, 2014). As Mayr (1994) writes in an article entitled "The Resistance to Darwinism and the Misconceptions on which it was Based"

Those authors who thought that mutations alone supplied the variability on which selection can act, often called natural selection a chance theory. They said that evolution had to wait for the lucky accident of a favorable mutation before natural selection could become active. This is now known to be completely wrong. Recombination provides in every generation abundant variation on which the selection of the relatively better adapted members of a population can work. (p. 38)

Mayr's claims are not accepted today. The "gene pool" theory, which Provine (2001, p. 201) now considers to be "one of the most artificial concepts of population genetics," appears to be a hand-waving theory that never fully materialized. Contemporary evolutionary geneticists do not view the abundance of variation in the "gene pool", and the ability of recombination to produce new variation every generation, as the sine qua non of evolution (e.g., see Woodruff and Thompson, 1998; or the comment on recombination by Provine, 2001, p. 201). To the contrary, models that invoke new mutations not only are considered allowable, but are used so commonly that they sometimes are referenced as the default view (see Barrett and Schluter, 2008; Hermisson and Pennings, 2005).

A new light is cast on the works of early geneticists by the realization that contemporary evolutionary geneticists (1) remain advocates of Mendelism, mutation and selection, (2) have undermined or discarded the claims that re-established Darwinism, and (3) hold views about variational causes of saltation, creativity, parallelism, and directionality that are understood historically to be non-Darwinian or anti-Darwinian. Their Mendelian-Mutationist view was a post-Darwinian, preModern Synthesis, featuring a robust skepticism of adaptationism and an emphasis - lacking in the Modern Synthesis but present in contemporary thinking (Pigliucci, 2009) - on saltation, stochasticity, individual events of mutation, and the creative or dispositional role of the process of variation. Contemporary evolutionists may align themselves with Darwin and his followers, imagining that they have nothing in common with the "notorious skeptics" of the eclipse period, with their "mystical ideas" (Charlesworth and Charlesworth, 2009), yet contem- 
porary neutralist, mutationist and evo-devo perspectives would have been rejected from the Modern Synthesis for being non-Darwinian.

This view again raises numerous questions. It is no less whiggish than the classical view: we simply have shifted the point of reference from 1959 to the present. Perhaps the most interesting question is how well the scientists who earned their place in the classical view truly understood the implications of identifying with Darwin and rejecting Punnett, Morgan and Bateson. Clearly they rejected a caricature called "mutationism" - evolution by dramatic mutations without selection. Yet, just as Fisher never tried to understand Bateson's views, the evolutionists who emerged from the "eclipse" with a synthetic view may have treated the early geneticists as a poisoned well, ignoring their views, and imagining that the combination of Mendelism, mutation and selection was theirs to claim on behalf of Darwin - or rather, on behalf of a reinvented version of Darwin as an unfulfilled Mendelian.

For practical reasons, we chose to restrict this study to the major works of four early geneticists known for their heterodox evolutionary views. There are various ways in which a change in scope or approach might yield a different story. Our picture of an early synthesis is shaped significantly by our treatment of de Vries and our decision to include Punnett. De Vries is the outlier in this group of four, and thus we construct a "Mendelian-mutationist synthesis" largely without his distinctive views. Yet his actual historical influence in defining a scientific alternative to Darwinism might have been stronger. Our inclusion of Punnett is justifiable, yet he (alone) could be re-classified as part of the second wave of early Mendelians, and if so, our story again would be different. For instance, if we placed Bateson, de Vries and Morgan perhaps with Johannsen - in a first wave of genetical founders, we could attribute them with a powerful and successful critique of Darwin's theory, but it might be more difficult to identify a shared alternative view among these four.

The second wave of pre-1910 geneticists, including Punnett, Lock, Pearl, East, Jennings, et al., clearly developed a synthetic view before 1918. From Kim's (1994) analysis of how the multifactorial view emerged, we suspect that focusing on the contributions of this second wave (e.g., using the list of early geneticists provided by Buttolph, 2008) would further undermine the notion of an "eclipse."

None of this would affect our arguments that the early geneticists' critique of Darwin's theory has a sound basis; that the conceptual foundations of evolutionary genetics were laid by geneticists during the "eclipse"; and that, relative to their view of evolution, and to contem- 
porary views, the Modern Synthesis appears as an unwarranted restriction.

\section{Acknowledgments}

We thank Eric Haag, John Beatty and Dave McCandlish for discussion. We thank two anonymous reviewers for detailed comments. The identification of any specific commercial products is for the purpose of specifying a protocol, and does not imply a recommendation or endorsement by the National Institute of Standards and Technology.

\section{Open Access}

This article is distributed under the terms of the Creative Commons Attribution License which permits any use, distribution, and reproduction in any medium, provided the original author(s) and the source are credited.

\section{References}

Adams, M.B. 1980. "Sergei Chetverikov, the Kol'tsov Institute, and the Evolutionary Synthesis." E. Mayr and W. Provine (eds.), The Evolutionary Synthesis. Cambridge, MA: Harvard University Press, pp. 242-278.

Allen, G. 1969. "Hugo de Vries and the Reception of the "Mutation Theory." Journal of the History of Biology 2(1): 55-87.

1978. Thomas Hunt Morgan: The Man and His Science. Princeton: Princeton University Press.

-1980. "The Evolutionary Synthesis: Morgan and Natural Selection Revisited." E. Mayr and W. Provine (eds.), The Evolutionary Synthesis. Cambridge, MA: Harvard University Press, pp. 356-382.

Amundson, R. 2005. The Changing Role of the Embryo in Evolution. Cambridge Studies in Philosophy and Biology. Cambridge, UK: Cambridge University Press.

Arthur, W. 2000. "The Concept of Developmental Reprogramming and the Quest for an Inclusive Theory of Evolutionary Mechanisms." Evolution and Development 2(1): 49-57.

2004. Biased Embryos and Evolution. Cambridge: Cambridge University Press.

Ayala, F.J., and Fitch, W.M. 1997. "Genetics and the Origin of Species: An Introduction." Proceedings of the National Academy of Sciences of the United States of America 94(15): 7691-7697.

Balogh, A.C., and Leimar, O. 2005. "Mullerian Mimicry: An Examination of Fisher's Theory of Gradual Evolutionary Change." Proceedings. Biological Sciences/The Royal Society 272(1578): 2269-2275. 
Barrett, R.D., and Schluter, D. 2008. "Adaptation from Standing Genetic Variation." Trends in Ecology \& Evolution 23(1): 38-44.

Bateson, W. 1894. Materials for the Study of Variation, Treated with Especial Regard to Discontinuity in the Origin of Species. London: Macmillan.

1902. Mendel's Principles of Heredity: A Defense. Cambridge: Cambridge University Press.

-1909a. "Heredity and Variation in Modern Light." A.C. Seward (ed.), Darwin and Modern Science: Essays in Commemoration of the Centenary of the Birgh of Charles Darwin and of the Fiftieth Anniversary of the Publication of the Origin of Species. London: Cambridge, pp. 85-101.

— 1909b. Mendel's Principles of Heredity. New York: Putnam's Sons. 1914. "Inaugural Address." Nature 93: 635-642.

1922. "Evolutionary Faith and Modern Doubts." Science 55: 55-61.

Bateson, W., and Saunders, E.R. 1902. "The Facts of Heredity in the Light of Mendel's Discovery." Reports to the Evolution Committee of the Royal Society I: 125-160.

Beatty, J. 2010. Reconsidering the Importance of Chance Variation." M. Pigliucci and G. Müller (eds.), Evolution: The Extended Synthesis. Cambridge, MA: MIT Press.

Bennett, J.H. 1983. Natural Selection, Heredity and Eugenics. Oxford: Oxford University Press.

Blount, Z.D., Borland, C.Z., and Lenski, R.E. 2008. "Historical Contingency and the Evolution of a Key Innovation in an Experimental Population of Escherichia coli." Proceedings of the National Academy of Sciences of the United States of America 105(23): 7899-7906.

Bowler, P. J. 1978. "Hugo De Vries and Thomas Hunt Morgan: The Mutation Theory and the Spirit of Darwinism." 35: 55-73. 1983. The Eclipse of Darwinism. Baltimore: Johns Hopkins University Press. 1988. The non-Darwinian revolution: reinterpreting a historical myth. Baltimore: Johns Hopkins University Press.

— 2003. Evolution: The History of An Idea, 3rd ed. Los Angeles: University of California Press.

Buttolph, M. 2008. One Hundred and One Mendelians. London: University College London.

Castle, W.E. 1905. “The Mutation Theory of Organic Evolution.” Science 21(536): 521524.

Charlesworth, B., and Charlesworth, D. 2009. "Darwin and Genetics." Genetics 183(3): 757-766.

Chouard, T. 2010. "Evolution: Revenge of the Hopeful Monster." Nature 463(7283): 864-867.

Christin, P.A., Weinreich, D.M., and Besnard, G. 2010. "Causes and Evolutionary Significance of Genetic Convergence." Trends in Genetics: TIG 26(9): 400-405.

Cock, A.G., and Forsdyke, D.R. 2008. Treasure Your Exceptions: The Science and Life of William Bateson. New York: Springer.

Cook, O.F. 1908. "The Mendelian Inheritance of Mutations." Science 28(707): 86-88. Coyne, J.A., and Orr, H.A. 2004. Speciation. Sunderland, MA: Sinauer Associates.

Crew, F.A. 1968. "R. C. Punnett." Genetics 58(1): 1-7.

Cronin, H. 1991. The Ant and the Peacock. Cambridge: Cambridge University Press.

Cuénot, L. 1909. "Recent Views of L. Cuenot on the Origin of Species by Mutation." Science 30(778): 768-769. 
Cunningham, C.W., Jeng, K., Husti, J., Badgett, M., Molineux, I.J., Hillis, D.M., and Bull, J.J. 1997. "Parallel Molecular Evolution of Deletions and Nonsense Mutations in Bacteriophage T7." Molecular Biology and Evolution 14(1): 113-116.

Darwin, C. 1868. Variation of Animals and Plants under Domestication. London: Murray.

-1872. On the Origin of Species, 6th ed. London: John Murray.

Davenport, C.B. 1909. "Mutation." Fifty Years of Darwinism: Modern Aspects of Evolution. New York: Henry Holt and Company, pp. 160-181.

Dawkins, R. 1987. The Blind Watchmaker. New York: W.W. Norton and Company.

de Vries, H. 1901. Die MutationsTheorie: Versuche und Beobachtungen, uber die Enstehung vom Arten in Pflanzenreich. Leipzig: Veit.

-1905. Species and Varieties: Their Origin by Mutation. Chicago: The Open Court Publishing Company.

1909a. The Mutation Theory. Trans. J.B. Famer and A.D. Darbishire. Chicago: Open Court.

1909b. "Variation." A.C. Seward (ed.), Darwin and Modern Science: Essays in Commemoration of the Centenary of the Birgh of Charles Darwin and of the Fiftieth Anniversary of the publication of the Origin of Species. London: Cambridge, pp. 6684.

Dean, A.M. 2012. Evolution: A View from the 21st Century. Microbe Magazine, March.

Denver, D.R., Howe, D.K., Wilhelm, L.J., Palmer, C.A., Anderson, J.L., Stein, K.C., Phillips, P.C., and Estes, S. 2010. "Selective Sweeps and Parallel Mutation in the Adaptive Recovery from Deleterious Mutation in Caenorhabditis elegans." Genome Research 20(12): 1663-1671.

Dietrich, M.R. 2003. "Richard Goldschmidt: Hopeful Monsters and Other 'Heresies'." Nature Reviews Genetics 4(1): 68-74.

Dobzhansky, T. 1937. Genetics and the Origin of Species. New York: Columbia University Press.

Dobzhansky, T. 1974. "Chance and Creativity in Evolution." F.J. Ayala and T. Dobzhansky (eds.), Studies in the Philosophy of Biology: Reduction and Related Problems. Berkeley and Los Angeles: University of California Press, pp. 307-338.

Eck, R.V., and Dayhoff, M.O. 1966. Atlas of Protein Sequence and Structure 1966. Washington, DC: National Biomedical Research Foundation.

Eiseley, L. 1958. Darwin's Century: Evolution and the Men Who Discovered It. Garden City, New York: Doubleday \& Company Inc.

Eldredge, N. 2001. The Triumph of Evolution and the Failure of Creationism. New York: W H Freeman \& Co.

Fisher, R.A. 1918. "The Correlation Between Relatives on the Supposition of Mendelian Inheritance." Philosophical Transactions of the Royal Society of Edinburgh 52: 399-433.

1930. The Genetical Theory of Natural Selection. London: Oxford University Press. 1932. "The Bearing of Genetics on Theories of Evolution." Science Progress 27: 273-287.

Ford, E.B. 1938. "The Genetic Basis of Adaptation." G.R. de Beer (ed.), Evolution, International Journal of Organic Evolution. Oxford: Clarendon Press, pp. 43-56.

Freeman, S., and Herron, J.C. 1998. Evolutionary Analysis. Upper Saddle River, New Jersey: Prentice-Hall. 
Froggatt, P., and Nevin, N.C. 1971. "The 'Law of Ancestral Heredity' and the Mendelian-Ancestrian Controversy in England, 1889-1906." Journal of Medical Genetics 8(1): $1-36$.

Gayon, J. 1998. Darwinism's Struggle for Survival: Heredity and the Hypothesis of Natural Selection. Trans. M. Cobb. Cambridge, UK: Cambridge University Press.

Gillespie, J.H. 1998. Population Genetics: A Concise Guide. Baltimore, MD: Johns Hopkins University Press.

Goldschmidt, R.B. 1911. Einführung in die Vererbungswissenschaft in zwanzig Vorlesungen für Studierende, Ärzte, Züchter. Leipzig: W. Engelmann.

Gould, S.J. 1977. Ever Since Darwin. New York: W.W. Norton \& Co.

— 2002. The Structure of Evolutionary Theory. Cambridge, MA: Harvard University Press.

Hancock, J.M., and Vogler, A.P. 2000. "How Slippage-Derived Sequences are Incorporated into rRNA Variable-Region Secondary Structure: Implications for Phylogeny Reconstruction." Molecular Phylogenetics and Evolution 14(3): 366-374.

Hartl, D.L., and Clark, A.G. 1997. Principles of Population Genetics. Sunderland, MA: Sinauer.

Hendrikse, J.L., Parsons, T.E., and Hallgrimsson, B. 2007. "Evolvability as the Proper Focus of Evolutionary Developmental Biology." Evolution \& Development 9(4): 393 401.

Hermisson, J., and Pennings, P.S. 2005. "Soft Sweeps: Molecular Population Genetics of Adaptation from Standing Genetic Variation." Genetics 169(4): 2335-2352.

Hoquet, T. 2010. "Non-Evolutionary Mutants? A Note on the Castorrex Rabbit." L. Campos and A. von Schwerin (eds.), Making Mutations: Objects, Practices, Contexts. Berlin: Max-Planck-Institut für Wissenschaftsgeschichte, pp. 85-108.

Hull, D.L. 1985. "Darwinism as a Historical Entity: A Historiographic Proposal." D. Kohn (ed.), The Darwinian Heritage. Princeton: Princeton University Press.

Huxley, J.S. 1942. Evolution: The Modern Synthesis. London: George Allen \& Unwin.

Johannsen, W.L. 1909. Elemente der exakten Erblichkeitslehre. Jena: Gustav Fischer.

Kim, K-M. 1994. Explaining Scientific Consensus: The Case of Mendelian Genetics. The Conduct of Science Series. New York: Guilford Press.

Kimura, M. 1983. The Neutral Theory of Molecular Evolution. Cambridge: Cambridge University Press.

Kimura, M., and Maruyama, T. 1969. "The Substitutional Load in a Finite Population." Heredity 24(1): 101-114.

King, J.L. 1971. "The Role of Mutation in Evolution." L.M. Le Cam, J. Neyman, and E.L. Scott (eds.), Sixth Berkeley Symposium on Mathematical Statistics and Probability. Berkeley, California: University of California Press.

King, J.L., and Jukes, T.H. 1969. "Non-Darwinian Evolution.” Science 164: 788-797.

Kingsland, S.E. 1991. "The Battling Botanist: Daniel Trembly MacDougal, Mutation Theory, and the Rise of Experimental Evolutionary Biology in America, 19001912." Isis 82(3): 479-509.

Kirschner, M.W., and Gerhart, J.C. 2005. The Plausibility of Life: Resolving Darwin's Dilemma. New Haven: Yale University Press.

Koonin, E.V. 2011. The Logic of Chance: The Nature and Origin of Biological Evolution. Upper Saddle River, NJ: Financial Times Press Science.

Macey, J.R., Larson, A., Ananjeva, N.B., and Papenfuss, T.J. 1997. "Replication Slippage May Cause Parallel Evolution in the Secondary Structures of Mitochondrial Transfer RNAs." Molecular Biology and Evolution 14(1): 30-39. 
MacKenzie, D. 1981. "Sociobiologies in Competition: The Biometrician-Mendelian Debate." C. Webster (ed.), Biology, Medicine and Society 1840-1940. Cambridge: Cambridge University Press, pp. 243-288.

Mallet, James. 2013. "Darwin and Species." Michael Ruse (ed.), The Cambridge Encyclopedia of Darwin and Evolutionary Thought. New York: Cambridge University Press, pp. 109-115.

Martin, A., and Orgogozo, V. 2013. "The Loci of Repeated Evolution: A Catalog of Genetic Hotspots of Phenotypic Variation." Evolution 67(5): 1235-1250.

Maynard Smith, J., Burian, R., Kauffman, S., Alberch, P., Campbell, J., Goodwin, B., Lande, R., Raup, D., and Wolpert, L. 1985. "Developmental Constraints and Evolution." The Quarterly Review of Biology 60(3): 265-287.

Mayr, E. 1963. Animal Species and Evolution. Cambridge, MA: Harvard University Press.

1980. "Some Thoughts on the History of the Evolutionary Synthesis." E. Mayr and W. Provine (eds.), The Evolutionary Synthesis. Cambridge, MA: Harvard University Press, pp. 1-48.

— 1982. The Growth of Biological Thought: Diversity, Evolution, and Inheritance. Cambridge, MA: Harvard University Press.

1988. Toward a New Philosophy of Biology. Cambridge, MA: Harvard University Press.

- 1991. One Long Argument: Charles Darwin and the Genesis of Modern Evolutionary Thought. Cambridge, MA: Harvard University Press.

- 1994. "The Resistance to Darwinism and the Misconceptions on Which It was

Based." J.H. Campbell and J.W. Schopf (eds.), Creative Evolution?! London: Jones \& Bartlett Inc., pp. 35-46.

McCandlish, D.L., and Stoltzfus, A. 2014. Modeling Evolution Using the Probability of

Fixation: History and Implications. Quarterly Review of Biology, in press.

Meijer, O.G. 1985. 'Hugo de Vries no Mendelian?' Annals of Science 42: 189-232.

Metcalf, M.M. 1905. "Determinate Mutation." Science 21(531): 355-356.

Morgan, T.H. 1904. "The Origin of Species Through Selection Contrasted with Their Origin through the Appearance of Definite Variations." Popular Science Monthly 67: $54-65$.

1910. "The American Society of Naturalists Chance or Purpose in the Origin and Evolution of Adaptation." Science 31(789): 201-210.

- 1923. "The Bearing of Mendelism on the Origin of Species." The Scientific Monthly 16: 237-247.

1903. Evolution and Adaptation. New York: Macmillan.

1916. A Critique of the Theory of Evolution. Princeton, NJ: Princeton University Press.

1925. Evolution and Genetics, 2nd ed. Princeton: Princeton University Press.

1932. The Scientific Basis of Evolution, 1st ed. New York: W.W. Norton \& Co.

Mousseau, T.A., and Roff, D.A. 1987. "Natural Selection and the Heritability of Fitness Components." Heredity 59(Pt 2): 181-197.

Nei, M. 2013. Mutation-Driven Evolution. New York: Oxford University Press.

Nei, M., and Nozawa, M. 2011. "Roles of Mutation and Selection in Speciation: From Hugo de Vries to the Modern Genomic Era." Genome Biology and Evolution 3: 812 829.

Nordmann, A. 1992. "Darwinians at War: Bateson's Place in Histories of Darwinism." Synthese 91: 53-72. 
Norton, H.T.J. 1928. "Natural Selection and Mendelian Variation." Proceedings of the London Mathematical Society 28: 1-45.

Orr, H.A. 1996. "Dobzhansky, Bateson, and the Genetics of Speciation." Genetics 144(4): 1331-1335.

- 2002. "The Population Genetics of Adaptation: The Adaptation of DNA Sequences." Evolution, The International Journal of Organic Evolution 56(7): 13171330 .

2005. "The Genetic Theory of Adaptation: A Brief History." Nature Reviews Genetics 6(2): 119-127.

Ortmann, A.E. 1907. "Facts and Interpretations in the Mutation Theory." Science 25(631): 185-190.

Pagel, M. 2002. Encyclopedia of Evolution. New York: Oxford University Press.

Pearson, K. 1906. "Walter Frank Raphael Weldon. 1860-1906." Biometrika 5: 1-52.

Peterson, E.L. 2008. "William Bateson from Balanoglossus to Materials for the Study of Variation: The Transatlantic Roots of Discontinuity and the (Un)Naturalness of Selection." Journal of the History of Biology 41(2): 267-305.

Pigliucci, M. 2009. "An Extended Synthesis for Evolutionary Biology." Annals of the New York Academy of Sciences 1168: 218-228.

Poulton, E.B. 1909. Fifty Years of Darwinism: Modern Aspects of Evolution. New York: Henry Holt and Company, pp. 8-56.

Provine, W.B. 1971. The Origins of Theoretical Population Genetics. Chicago: University of Chicago Press.

1978. "The Role of Mathematical Population Geneticists in the Evolutionary Synthesis of the 1930s and 1940s." Studies in the History of Biology 2: 167-192.

1986. Sewall Wright and Evolutionary Biology. Chicago: University of Chicago Press.

2001. The Origins of Theoretical Population Genetics, 2nd ed. Chicago: University of Chicago Press.

Punnett, R.C. 1905. Mendelism, 1st ed. London: MacMillan and Bowes.

— 1911. Mendelism, 3rd ed. New York: MacMillan.

1913. "More Mendelism and Mimicry." Bedrock 2: 496.

1915. Mimicry in Butterflies. Cambridge: Cambridge University Press.

- 1930. "Genetics, Mathematics, and Natural Selection." Nature 126(3181): 595597.

Reid, G.A. 1913. "Modern Science and Modern Rhetoric." Bedrock 2: 215-243.

Richmond, M.L. 2006. "The 1909 Darwin Celebration. Reexamining Evolution in the Light of Mendel, Mutation, and Meiosis." Isis 97(3): 447-484.

— 2010. "Women in Mutation Studies: The Role of Gender in the Methods, Practices, and Results of Early Twentieth-Century Genetics." L. Campos and A. von Schwerin (eds.), Making Mutations: Objects, Practices, Contexts. Berlin: MaxPlanck-Institut für Wissenschaftsgeschichte, pp. 11-48.

Rogozin, I.B., Thomson, K., Csuros, M., Carmel, L., and Koonin, E.V. 2008. "Homoplasy in Genome-Wide Analysis of Rare Amino Acid Replacements: The Molecular-Evolutionary Basis for Vavilov's Law of Homologous Series." Biology Direct 3: 7.

Roll-Hansen, N. 1980. "The Controversy Between Biometricions and Mendelions: A Test Case for the Sociology of Scientific Knowledge." Social Science Information 19(3): 501-517. 
1989. "The Crucial Experiment of Wilhelm Johannsen." Biology and Philosophy 4(3): 303-329.

Sapp, Jan. 2003. Genesis: The Evolution of Biology. Oxford/New York: Oxford University Press.

Segerstråle, U. 2002. “Neo-Darwinism.” M. Pagel (ed.), Encyclopedia of Evolution. New York: Oxford University Press, pp. 807-810.

Shapiro, J. 2011. Evolution: A View from the 21st Century. New York: FT Press.

Shull, A.F. 1935. "Weismann and Haeckel: One Hundred Years." Science 81(2106): 443.

Shull, G.H. 1907. "Importance of the Mutation Theory in Practical Breeding." Proceedings of the American Breeders' Association 3: 60-67.

Smocovitis, V.B. 1996. Unifying Biology: The Evolutionary Synthesis and Evolutionary Biology. Princeton: Princeton University Press.

Stamhuis, I.H., Meijer, O.G., and Zevenhuizen, E.J. 1999. "Hugo de Vries on Heredity, 1889-1903. Statistics, Mendelian Laws, Pangenes, Mutations." Isis 90(2): 238-267.

Stern, D.L. 2000. "Evolutionary Developmental Biology and the Problem of Variation." Evolution, The International Journal of Organic Evolution 54(4): 1079-1091.

Stoltzfus, A. 2006. "Mutationism and the Dual Causation of Evolutionary Change." Evolution and Development 8(3): 304-317.

Stoltzfus, A., and Yampolsky, L.Y. 2009. "Climbing Mount Probable: Mutation as a Cause of Nonrandomness in Evolution." Journal of Heredity 100(5): 637-647.

Streisfeld, M.A., and Rausher, M.D. 2011. "Population Genetics, Pleiotropy, and the Preferential Fixation of Mutations During Adaptive Evolution." Evolution, International Journal of Organic Evolution 65(3): 629-642.

Stubbe, H. 1972. History of Genetics. Trans. T.R.W. Waters. Cambridge, MA: MIT Press.

Sturtevant, A.H. 2001. A History of Genetics. Cold Spring Harbor: Cold Spring Harbor Laboratory Press.

Theunissen, B. 1994. "Closing the Door on Hugo de Vries' Mendelism." Annals of Science 51(3): 225-248.

Vavilov, N.I. 1922. "The Law of Homologous Series in Variation." Journal of Heredity 12: 47-89.

Wallace, A.R. 1909. Letter to Edward Bagnall Poulton, 22 November 1909. Wallace Letters Online. http://www.nhm.ac.uk/research-curation/scientific-resources/collections/ library-collections/wallace-letters-online/4449/4748/T/details.html. Accessed 5 June 2013.

Winther, R.G. 2000. "Darwin on Variation and Heredity." Journal of the History of Biology 33: 425-455.

Wood, T.E., Burke, J.M., and Rieseberg, L.H. 2005. "Parallel Genotypic Adaptation: When Evolution Repeats Itself." Genetica 123(1-2): 157-170.

Woodruff, R.C., and Thompson, J.D. 1998. "Preface." R.C. Woodruff and J.D. Thompson (eds.), Mutation and Evolution. Contemporary Issues in Genetics and Evolution. Dordrecht: Kluwer. 